\title{
Biomarkers Predicting Tissue Pharmacokinetics of Antimicrobials in Sepsis: A Review
}

\author{
Maria Sanz Codina ${ }^{1}$ (D) Markus Zeitlinger ${ }^{1}$
}

Accepted: 13 December 2021 / Published online: 25 February 2022

(c) The Author(s) 2022

\begin{abstract}
The pathophysiology of sepsis alters drug pharmacokinetics, resulting in inadequate drug exposure and target-site concentration. Suboptimal exposure leads to treatment failure and the development of antimicrobial resistance. Therefore, we seek to optimize antimicrobial therapy in sepsis by selecting the right drug and the correct dosage. A prerequisite for achieving this goal is characterization and understanding of the mechanisms of pharmacokinetic alterations. However, most infections take place not in blood but in different body compartments. Since tissue pharmacokinetic assessment is not feasible in daily practice, we need to tailor antibiotic treatment according to the specific patient's pathophysiological processes. The complex pathophysiology of sepsis and the ineffectiveness of current targeted therapies suggest that treatments guided by biomarkers predicting target-site concentration could provide a new therapeutic strategy. Inflammation, endothelial and coagulation activation markers, and blood flow parameters might be indicators of impaired tissue distribution. Moreover, hepatic and renal dysfunction biomarkers can predict not only drug metabolism and clearance but also drug distribution. Identification of the right biomarkers can direct drug dosing and provide timely feedback on its effectiveness. Therefore, this might decrease antibiotic resistance and the mortality of critically ill patients. This article fills the literature gap by characterizing patient biomarkers that might be used to predict unbound plasma-to-tissue drug distribution in critically ill patients. Although all biomarkers must be clinically evaluated with the ultimate goal of combining them in a clinically feasible scoring system, we support the concept that the appropriate biomarkers could be used to direct targeted antibiotic dosing.
\end{abstract}

Markus Zeitlinger

markus.zeitlinger@meduniwien.ac.at

Maria Sanz Codina

maria.sanzcodina@meduniwien.ac.at

1 Department of Clinical Pharmacology, Medical University

of Vienna, Vienna, Austria 


\section{Graphical Abstract}

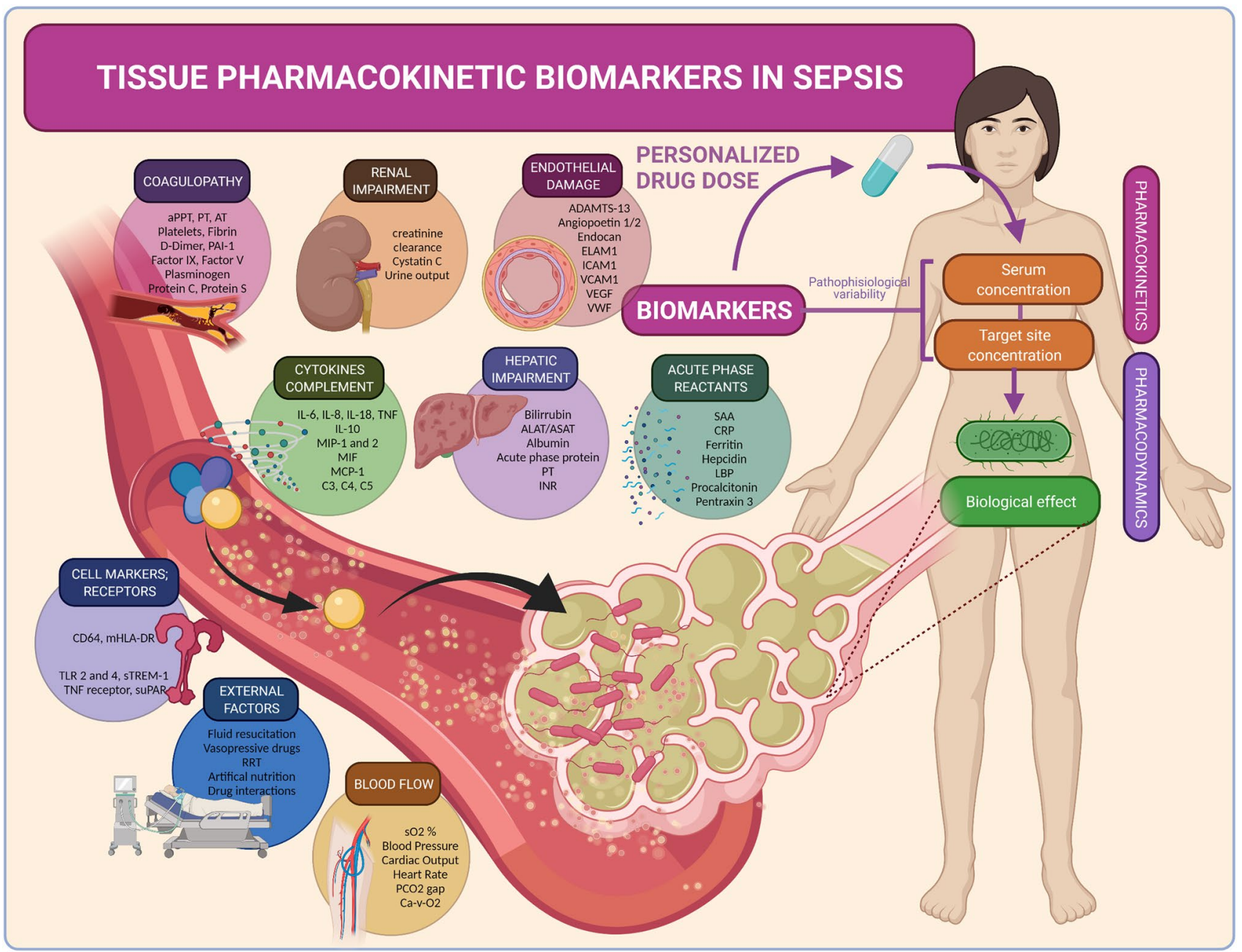

ADAMTS-13 a disintegrin-like and metalloprotease with thrombospondin type 1 motif no. 13, ALAT alanine amino transferase, APACHE IV Acute Physiology and Chronic Health Evaluation-IV, aPPT activated partial thromboplastin time, ASAT aspartate amino transferase, AT antithrombin, $\mathrm{Ca}-\mathrm{V}-\mathrm{O}_{2}$ oxygen content difference, arterial-venous, $C R P$ C-reactive protein, ELAM endothelial leukocyte adhesion molecule, $I C A M$ intercellular adhesion molecule, $I L$ interleukin, $I N R$ international normalized ratio, $L B P$ lipopolysaccharide-binding protein, $M C P$ monocyte chemoattractant protein, $m H L A$ monocytic human leukocyte antigen, $M I F$ migration inhibitory factor, $M I P$ macrophage inflammatory protein, $P A I$ plasminogen activator inhibitor, $P C \mathrm{O}_{2}$ partial pressure of carbon dioxide, $P T$ prothrombin time, $R R T$ renal replacement therapy, SAPSS III Simplified Acute Physiology Score-III, $s \mathrm{O}_{2}$ oxygen saturation, SOFA Sequential [Sepsis-related] Organ Failure Assessment, $s$ TREM soluble triggering receptor expressed on myeloid cells $1, T L R$ toll-like receptor, TNF tumor necrosis factor, VCAM vascular cell adhesion molecule, $V E G F$ vascular endothelial growth factor, $v W f$ von Willebrand factor 


\section{Key Points}

Pathophysiological changes in sepsis lead to pharmacokinetic variability and altered antibiotic infection site concentrations.

Biomarkers reflecting drug pharmacokinetics might help optimize antimicrobial dosing.

According to the pathophysiology of sepsis, the following host factors might be suitable to predict antibiotic target-site exposure in critically ill patients: inflammation, endotheliopathy, blood flow, coagulation, and hepatic and renal dysfunction. Prospective pharmacokinetic studies are needed.

\section{Introduction}

Sepsis is a life-threatening organ dysfunction resulting from a deregulated host response to infection (Fig. 1) [1]. The World Health Organization considers sepsis a global health emergency because 11 million sepsis-related deaths worldwide occur every year [2]. Thus, there is a call for global action to improve prevention, diagnostic, and treatment tools [3-5]. Part of this high mortality in critically ill patients has been linked to antibiotic treatment failure [6].

Several factors might lead to this treatment failure, including inadequate penetration of the antimicrobial to the target site [7-9], since site drug levels may substantially vary from the corresponding plasma drug concentrations [15]. Suboptimal antibiotic doses in the site of infection may also result in adverse reactions, toxicity, resistance, and higher costs [10]. Critically ill patient pathophysiology leads to highly variable systemic pharmacokinetics and altered tissue penetration of antibiotics [11]. Therefore, standardized doses might not fit patients in the intensive care unit (ICU), who have an increased risk of not receiving target-site therapeutic concentrations [10].

Various strategies have been proposed to improve antibiotic use, such as antibiotic stewardship [12, 13], therapeutic drug monitoring (TDM), and precision dosing [14-16]. Dose adjustments have recently shown promising evidence for improved outcomes and reduction of antimicrobial resistance [17]. In recent years, dosing nomograms and population-pharmacokinetic dosing software have appeared to optimize antibiotic use $[18,19]$. However, these techniques have a significant limitation: they predict the drug concentration in plasma, and rarely in the site of infection [20].

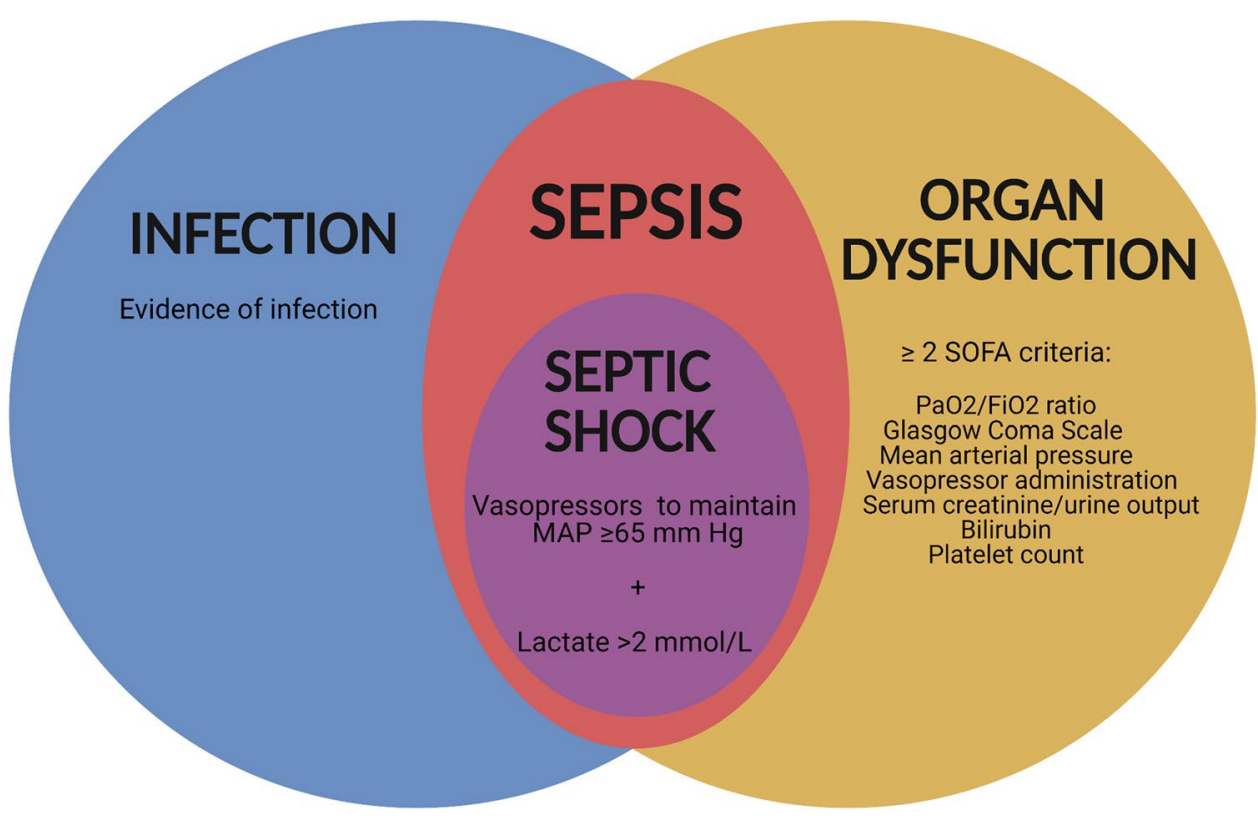

Fig. 1 The Sepsis-3 criteria. "Sepsis should be defined as life-threatening organ dysfunction caused by a dysregulated host response to infection [suspected or confirmed]" [192]. The SOFA (Sequential [Sepsis-related] Organ Failure Assessment) score can be used to determine organ dysfunction. Organ dysfunction representing sepsis is defined as an increase in the SOFA score of $\geq 2$ points. The SOFA score rates the functioning of six organ systems from 0 to 4 . A subtype of sepsis is septic shock, which requires a vasopressor to preserve a mean blood pressure of $\geq 65 \mathrm{mmHg}$, and by a serum lactate level $>2 \mathrm{mmol} / \mathrm{L}(>18 \mathrm{mg} / \mathrm{dL})$ without hypovolemia. $M A P$ mean arterial pressure, $\mathrm{PaO} 2 / \mathrm{FiO} 2$ ratio of arterial oxygen partial pressure to fractional inspired oxygen 
Table 1 Physiological antibiotic properties and implications for pharmacokinetics in critical illness

\begin{tabular}{lll}
\hline Pharmacokinetics & Lipid solubility & \\
\cline { 2 - 3 } & Hydrophilic antibiotics & Lipophilic antibiotics \\
\hline General & $\downarrow \mathrm{V}_{\mathrm{d}} ; \uparrow \mathrm{C}_{\mathrm{max}}, \downarrow$ intracellular penetration; renal clearance & $\uparrow \mathrm{V}_{\mathrm{d}} ; \downarrow \mathrm{C}_{\mathrm{max}} ; \uparrow$ intracellular penetration; hepatic clearance \\
In critically ill & $\uparrow \mathrm{V}_{\mathrm{d}} ; \uparrow / \downarrow$ renal clearance; dependent on renal function and PB & $\begin{array}{c}\text { Unchanged } \mathrm{V}_{\mathrm{d}} ; \uparrow / \downarrow \text { hepatic clearance; dependent on } \\
\text { hepatic function and PB }\end{array}$ \\
Examples & $\beta$-lactams, aminoglycosides, glycopeptides & Fluoroquinolones, macrolides, rifampicin, linezolid \\
\hline
\end{tabular}

$C_{\max }$ maximum plasma drug concentration, $P B$ protein binding, $V_{d}$ volume of distribution, $\uparrow$ and $\downarrow$ indicate increase and decrease, respectively

Determining the concentration at the infection site for individual patients is challenging, so biomarkers that might predict target-site concentrations are needed. Sepsis biomarkers have already been used to prove infection and help confirm a sepsis suspicion [21, 22], and procalcitoninguided antibiotic therapy is already a reality [23]. A retrospective study examined the accuracy of different markers and scoring systems for predicting tissue penetration of antimicrobials and found that oxygen saturation, serum lactate concentration, and the dose per unit time of norepinephrine administered were best correlated with tissue penetration [24]. Nevertheless, a gap remains in the literature linking such time-varying host biomarkers to target-site concentration and antibiotic exposure. Such knowledge would enable the stratification of patients with increased risk of treatment failure and individualize antibiotic treatment.
This review aims to characterize biomarkers that predict antibiotic pharmacokinetics in critically ill patients. Our objective is to summarize the effect of pathophysiological changes in critically ill patients on pharmacokinetics and how biomarkers might predict them. First, we give an overview of drug and host factors influencing pharmacokinetic changes. Then we propose and classify biomarkers that can predict this pharmacokinetic variability and thus the antibiotic concentration at the infection site.

\section{Methods}

We conducted a literature review in the MEDLINE, Google Scholar, and ISI Web of Science databases. We also identified references from relevant articles and from searches of the authors' extensive files. Search terms used were sepsis,

Table 2 Protein binding of antibiotics

\begin{tabular}{|c|c|c|}
\hline \multirow[t]{2}{*}{ Pharmacokinetics } & \multicolumn{2}{|l|}{ Protein binding } \\
\hline & High & Low \\
\hline General & $\begin{array}{l}\downarrow \text { Diffusion, } \downarrow \text { tissue penetration, } \\
\downarrow \text { antimicrobial activity }\end{array}$ & $\begin{array}{l}\uparrow \text { Diffusion, } \uparrow \text { tissue penetration, } \uparrow \text { antimi- } \\
\text { crobial activity }\end{array}$ \\
\hline In the critically ill & $\begin{array}{l}\uparrow \text { Diffusion, } \uparrow \text { tissue penetration, } \uparrow \\
\text { antimicrobial activity }\end{array}$ & Unchanged \\
\hline Examples & Ceftriaxone, doxycycline, ertapenem & Fluoroquinolones, fosfomycin, meropenem \\
\hline
\end{tabular}

$\uparrow$ and $\downarrow$ indicate increase and decrease, respectively

Table 3 PK/PD index predictors of efficacy in antibiotics

\begin{tabular}{|c|c|c|c|c|}
\hline $\mathrm{PK} / \mathrm{PD}$ index predictor & $\mathrm{PK} / \mathrm{PD}$ & Objective & Antibiotics & References \\
\hline$C_{\max } / \mathrm{MIC}$ & Concentration dependent & Maximize the concentration & $\begin{array}{l}\text { Aminoglycosides, fluoroquinolones, } \\
\text { ketolides, metronidazole, polymyxin }\end{array}$ & [29] \\
\hline $\mathrm{T}>\mathrm{MIC}$ & Time dependent & Maximize duration of exposure & $\begin{array}{l}\beta \text {-lactams, erythromycin, clarithromy- } \\
\text { cin, linezolid, lincosamides }\end{array}$ & {$[30]$} \\
\hline $\mathrm{AUC}_{0-24} / \mathrm{MIC}$ & $\begin{array}{l}\text { Concentration dependent } \\
\text { with time dependence }\end{array}$ & $\begin{array}{l}\text { Maximize the amount of drug expo- } \\
\text { sure }\end{array}$ & $\begin{array}{l}\text { Azithromycin, clindamycin, linezolid, } \\
\text { tetracyclines, daptomycin, fluoroqui- } \\
\text { nolones, aminoglycosides, tigecy- } \\
\text { cline, vancomycin }\end{array}$ & {$[31,32]$} \\
\hline
\end{tabular}

$A U C_{0-24}$ area under the plasma concentration-time curve from time zero to $24 \mathrm{~h}, C_{\max }$ maximum plasma drug concentration, $M I C$ minimum inhibitory concentration, $P K / P D$ pharmacokinetics/pharmacodynamics, $T>M I C$ time above MIC 
critically ill, pharmacokinetics, pharmacodynamics, biomarkers, and individual dosing. After the initial revision, we conducted individual searches for each relevant biomarker. We only reviewed English language articles. No date restrictions were set in these searches.

\section{Antibiotic Factors}

Antibiotics can be classed according to their physicochemical properties and pharmacodynamic characteristics (Tables 1, 2 and 3).

\subsection{Antibiotic Characteristics According to Physicochemistry}

The physicochemical properties of antibiotics play a significant role in achieving target-site concentration by affecting the volume of distribution $\left(V_{\mathrm{d}}\right)$, unbound concentrations, and clearance [25].

\subsection{Lipid Solubility}

Compounds with higher lipid solubility penetrate more easily into lipid membranes and, therefore, can be distributed intracellularly and in adipose tissues. On the other hand, hydrophilic antibiotics have a lower $V_{\mathrm{d}}$ and are predominantly distributed in the intravascular and interstitial space. Lipophilic drugs tend to have higher protein binding than hydrophilic drugs and usually need to be metabolized before being excreted [26].

\subsubsection{Protein Binding}

Changes in protein binding (PB) might influence pharmacokinetic parameters. Since only the nonbonded drug can diffuse into the extracellular space, $\mathrm{PB}$ has a significant effect on the $V_{\mathrm{d}}$, so a reduction of $\mathrm{PB}$ could lead to higher target exposure. On the other hand, only the unbound drug can be metabolized and excreted [27]. As such, reduced PB might lead to an increase of the unbound ratio (unbound/ bound drug), increasing the amount of drug available for clearance. Since this complex interaction is difficult to predict and might differ between antibiotics, it is important to measure both total and free drug in pharmacological studies. Usually this is not feasible for clinical TDM.

\subsection{Antibiotic Characteristics According to Pharmacokinetic/Pharmacodynamic Index}

Antibiotics are also classified with the pharmacokinetic/ pharmacodynamic (PK/PD) index using the minimum inhibitory concentration (MIC) to measure the potency of drug-microorganism interaction. Once the PK/PD ratio has been determined, it is possible to tailor the pharmacodynamics target linked to the highest bactericidal activity. PK/PD ratios have benefited clinical practice and have been included in the development and approval of new antibiotics [28]. Antibiotics are classified as follows.

\subsubsection{Time-Dependent Antibiotics}

Time-dependent antibiotics are most effective if their concentration is maintained for as long as possible above the MIC (the lowest concentration should be at least four times the MIC) [29].

\subsubsection{Concentration-Dependent Antibiotics}

Concentration-dependent antibiotics require high concentration peaks as bacterial clearance depends on concentration rather than duration of exposure [30].

\subsubsection{Concentration- and Time-Dependent Antibiotics}

The area under the plasma concentration-time curve for 24 $\mathrm{h}$ for the MIC is the PK/PD index used to characterize antimicrobial efficacy. Dose optimization of these drugs aims to maximize overall exposure [31,32].

\subsection{Antibiotic Use in the Intensive Care Unit}

Inadequate antimicrobial therapy correlates with reduced survival in critically ill patients [33]. The most used antibiotics in European ICUs are $\beta$-lactams, glycopeptides, and quinolones, with other antibiotics reserved for severe bacterial infections with antibiotic resistance [34]. Table 4 provides the characteristics of the most commonly used antibiotics in the ICU. Most of these antibiotics are hydrophilic, renally cleared, and time dependent. Therefore, their limited tissue distribution and the fluctuations of renal function in the critically ill make these antibiotics very susceptible to pharmacokinetic variability and target attainment failure $[35,36]$.

\section{Host Factors}

\subsection{Sepsis Pathophysiology}

Sepsis is caused by a dysregulated immune response (Fig. 2). An increase in the production of proinflammatory cytokines by the innate immune system can result in a "cytokine storm." This inflammatory state results in endothelial damage and coagulation alterations [37]. Blood flow is impaired, leading to heterogeneous organ perfusion, mitochondrial dysfunction, cellular hypoxia, and organ dysfunction and 
Table $4 \mathrm{PK} / \mathrm{PD}$ characteristics of common antibiotics used in intensive care units

\begin{tabular}{|c|c|c|c|c|c|c|c|c|c|}
\hline Antibiotic & Gram+/- & $\begin{array}{l}\text { Mechanism of } \\
\text { action }\end{array}$ & $\begin{array}{l}\mathrm{PK} / \mathrm{PD} \\
\text { index }\end{array}$ & $V_{\mathrm{d}}(\mathrm{L} / \mathrm{kg})$ & $\mathrm{PB}(\%)$ & $t_{1 / 2}(\mathrm{~h})$ & Clearance & Solubility & References \\
\hline \multicolumn{10}{|l|}{$\beta$-lactam } \\
\hline Meropenem & $\mathrm{G}+/ \mathrm{G}-$ & Bactericidal & $\mathrm{T}>\mathrm{MIC}$ & 0.25 & 2 & 1 & Renal & Hydrophilic & {$[193,194]$} \\
\hline Cefuroxime & $\mathrm{G}+/ \mathrm{G}-$ & Bactericidal & $\mathrm{T}>\mathrm{MIC}$ & $6.4-9.1$ & $33-50$ & 1.1 & Renal & Hydrophilic & [195] \\
\hline Cefazolin & $\mathrm{G}+/ \mathrm{G}-$ & Bactericidal & $\mathrm{T}>\mathrm{MIC}$ & 0.14 & $80-90$ & 1.8 & Renal & Hydrophilic & {$[196,197]$} \\
\hline $\begin{array}{l}\text { Piperacillin/ } \\
\text { tazobactam }\end{array}$ & $\mathrm{G}+/ \mathrm{G}-$ & Bactericidal & $\mathrm{T}>\mathrm{MIC}$ & $0.38 / 0.31$ & $25 / 30$ & $1.14 / 0.92$ & Renal & Hydrophilic & {$[198,199]$} \\
\hline $\begin{array}{l}\text { Ampicillin/sul- } \\
\text { bactam }\end{array}$ & $\mathrm{G}+/ \mathrm{G}-$ & Bactericidal & $\mathrm{T}>\mathrm{MIC}$ & $0.16 / 0.1$ & $28 / 38$ & $1 / 1$ & Renal & Hydrophilic & [200-202] \\
\hline $\begin{array}{r}\text { Ceftolozane/ } \\
\text { tazobactam }\end{array}$ & $\mathrm{G}+/ \mathrm{G}-$ & Bactericidal & $\mathrm{T}>\mathrm{MIC}$ & $0.19 / 0.31$ & $21 / 30$ & $2.77 / 0.92$ & Renal & Hydrophilic & [203-205] \\
\hline \multicolumn{10}{|l|}{ Glycopeptide } \\
\hline Teicoplanin & G+ & Bacteriostatic & $\begin{array}{l}\text { AUC/MIC } \\
\text { T>MIC }\end{array}$ & $0.7-1.4$ & 90 & $70-100$ & Renal & Hydrophilic & [206] \\
\hline Vancomycin & G+ & Bactericidal & $\begin{array}{l}\text { AUC/MIC } \\
\mathrm{T}>\mathrm{MIC}\end{array}$ & $0.4-1$ & $10-50$ & 6 & Renal & Hydrophilic & [207] \\
\hline \multicolumn{10}{|l|}{ Lipopeptide } \\
\hline Daptomycin & G+ & Bactericidal & $\begin{array}{l}\mathrm{AUC} / \mathrm{MIC} \\
\mathrm{C}_{\max } / \mathrm{MIC}\end{array}$ & 0.1 & 90 & $7.5-9$ & Renal & $\begin{array}{l}\text { Hydrophilic core } \\
\text { lipophilic tail }\end{array}$ & [208-210] \\
\hline $\begin{array}{l}\text { Fosfomycin } \\
\text { Glycylcycline }\end{array}$ & $\mathrm{G}+/ \mathrm{G}-$ & Bactericidal & $\mathrm{T}>\mathrm{MIC}$ & $1.4-2.4$ & 10 & $2.9-8.5$ & Renal & Hydrophilic & [211-213] \\
\hline $\begin{array}{l}\text { Tigecycline } \\
\text { Fluoroquinolone }\end{array}$ & $\mathrm{G}+/ \mathrm{G}-$ & Bacteriostatic & AUC/MIC & $7-10$ & $71-89$ & $37-67$ & Hepatic & Lipophilic & {$[214,215]$} \\
\hline Ciprofloxacin & $\mathrm{G}+/ \mathrm{G}-$ & Bactericidal & AUC/MIC & $1.74-5$ & $20-30$ & $3-4$ & Hepatic & Lipophilic & [216] \\
\hline $\begin{array}{l}\text { Moxifloxacin } \\
\text { Metronidazole }\end{array}$ & $\mathrm{G}+/ \mathrm{G}-$ & Bactericidal & AUC/MIC & 1.65 & $30-50$ & 12 & Hepatic & Lipophilic & [217] \\
\hline $\begin{array}{l}\text { Metronidazole } \\
\text { Aminoglycosides }\end{array}$ & Anaerobic & Bactericidal & AUC/MIC & $0.51-1.1$ & $<20$ & $6-10$ & Renal & Hydrophilic & [218] \\
\hline Gentamicin & $\mathrm{G}+/ \mathrm{G}-$ & Bactericidal & $\begin{array}{l}\mathrm{C}_{\max } / \mathrm{MIC} \\
\mathrm{AUC} / \mathrm{MIC}\end{array}$ & $0.22-0.27$ & $0-30$ & 1.25 & Renal & Hydrophilic & [219] \\
\hline Amikacin & $\mathrm{G}+/ \mathrm{G}-$ & Bactericidal & $\begin{array}{l}\mathrm{C}_{\max } / \mathrm{MIC} \\
\text { AUC/MIC }\end{array}$ & $0.22-0.27$ & $<10$ & $2-3$ & Renal & Hydrophilic & {$[220]$} \\
\hline Tobramycin & $\mathrm{G}+/ \mathrm{G}-$ & Bactericidal & $\begin{array}{l}\mathrm{C}_{\max / \mathrm{MIC}} \\
\mathrm{AUC} / \mathrm{MIC}\end{array}$ & 0.25 & - & $2.2-2.4$ & Renal & Hydrophilic & {$[221]$} \\
\hline \multicolumn{10}{|l|}{ Macrolides } \\
\hline Azithromycin & $\mathrm{G}+/ \mathrm{G}-$ & Bacteriostatic & AUC/MIC & $0.35-0.5$ & $<50$ & $11-14$ & Hepatic & Lipophilic & {$[222,223]$} \\
\hline $\begin{array}{l}\text { Erythromycin } \\
\text { Polymyxins }\end{array}$ & $\mathrm{G}+/ \mathrm{G}-$ & Bacteriostatic & AUC/MIC & $0.6-1.1$ & $80-90$ & $1.4-2.8$ & Hepatic & Lipophilic & [224] \\
\hline Colistin & G- & Bactericidal & AUC/MIC & 0.2 & $>50$ & 0.5 & $\begin{array}{l}\text { Renal (prod- } \\
\text { rug) }\end{array}$ & Hydrophilic & {$[225]$} \\
\hline \multicolumn{10}{|l|}{ Oxazolidinones } \\
\hline Linezolid & G+ & $\begin{array}{l}\text { Bactericidal, } \\
\text { bacteriostatic }\end{array}$ & $\begin{array}{l}\text { AUC/MIC } \\
\text { T>MIC }\end{array}$ & 0.7 & 31 & $4-6$ & Hepatic, renal & Lipophilic & [226] \\
\hline
\end{tabular}

$A U C$ area under the plasma concentration-time curve, $C_{\max }$ maximum plasma drug concentration, $G+/ G-$ Gram positive/negative, $M I C$ minimum inhibitory concentration, $P B$ protein binding, $P K / P D$ pharmacokinetics/pharmacodynamics, $T>M I C$ time above MIC, $t_{1 / 2}$ elimination halflife, $V_{d}$ volume of distribution

failure. Consequently, there is an increased capillary leak, resulting in hypotension associated with a hyperdynamic cardiovascular state. Moreover, body fluid increases, especially after resuscitation [38]. Following, there might be an immunosuppression phase that fails to control the infection [39]. Such inflammatory and immunosuppressive states are thought to be overlapping, which further complicates the monitoring of the disease [40]. Ultimately, inflammation and 


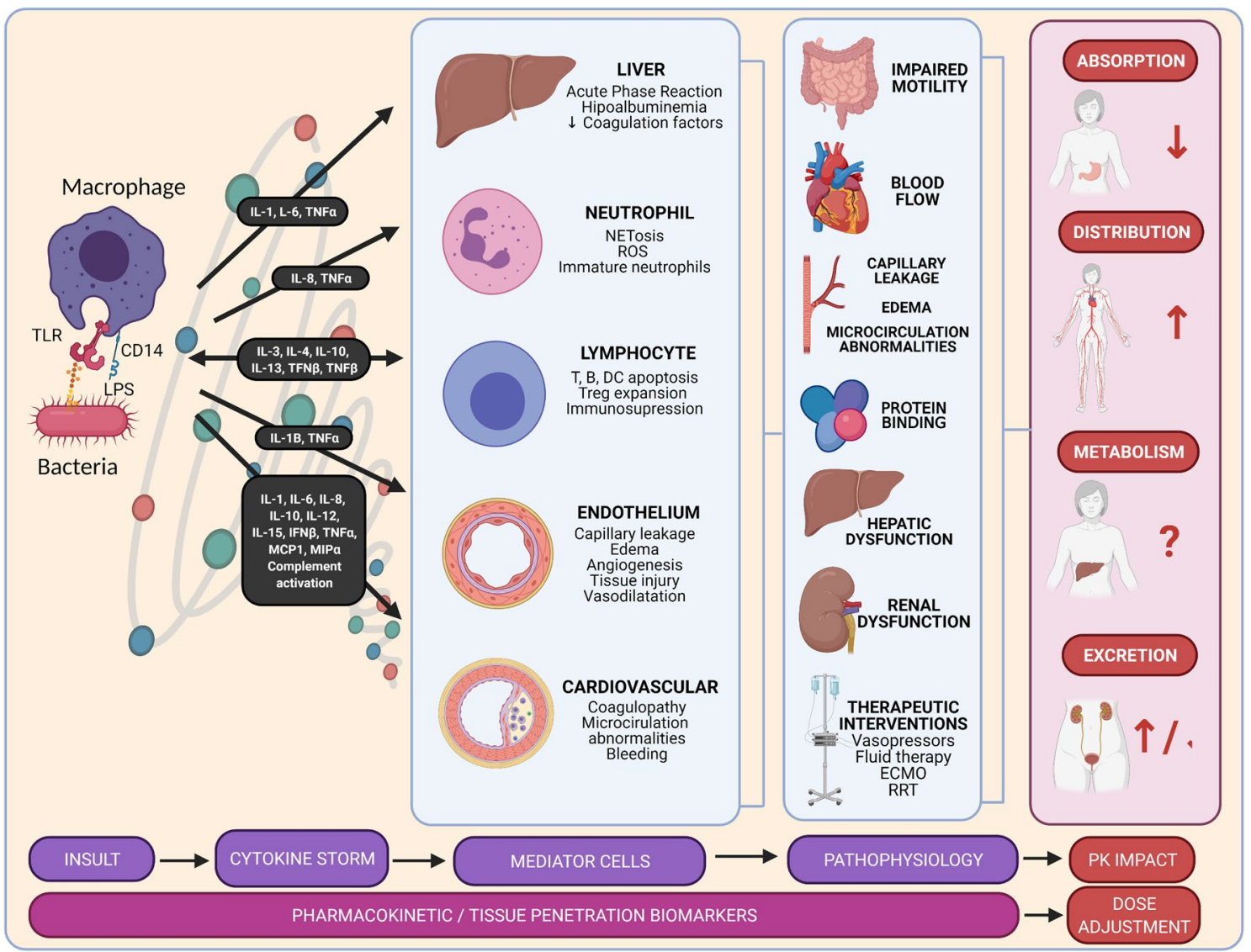

Fig. 2 Sepsis pathophysiology and its implications in pharmacokinetics. Sepsis occurs when there is a dysregulated immune response. During infections, pathogen-associated molecular patterns, such as LPS or peptidoglycan, bind to pattern-recognizing receptors, such as TLRs, potentiated by the CD14 receptors. As a result, the immune system might respond with an exaggerated, uncontrolled, and massive release of proinflammatory cytokines. This cytokine storm results in the continuous activation and expansion of immune cells, lymphocytes, and macrophages from the circulation to the infection, with destructive effects on human tissue. Consequently, endothelial cell interactions destabilize vascular barrier damages and there is multio-

coagulopathy cause the vascular and organ damage characteristic of severe sepsis and septic shock and, lastly, cause organ failure and death.

\subsection{Pharmacokinetic Alterations in Septic Patients}

The unique pathophysiology of sepsis alters the components of pharmacokinetics. Figure 2 provides an overview of how the sepsis pathogenesis drives pharmacokinetic alterations.

\subsubsection{Absorption}

Critically ill patients have unpredictable oral bioavailability because of their delayed and impaired absorption. Gut motility is reduced, so gastric emptying is delayed and splanchnic rgan failure. The overwhelming systemic response causes an increase in cardiac output, fluid extravasation, a decrease in protein binding, and hepatic and renal dysfunction. Together with the aggressive therapeutic interventions in the critically ill, these pathophysiological changes might lead to variability in pharmacokinetics (absorption, distribution, metabolism, and excretion). DC dendritic cell, ECMO extracorporeal membrane oxygenation, IFN interferon, $I L$ interleukin, $L P S$ lipopolysaccharide, $M C P$ monocyte chemoattractant protein, $M I P$ macrophage inflammatory protein, $P K$ pharmacokinetics, $R O S$ reactive oxygen species, $R R T$ renal replacement therapy, $T L R$ toll-like receptor, $T N F$ tumor necrosis factor, Treg T-regulatory cells

blood flow reduced. The delay in gastric emptying prolongs the time for the antibiotic to reach the maximum concentration. An impaired peripheral blood flow also compromises absorption from subcutaneous and intramuscular injection. Because of these alterations, antibiotics in the ICU are usually initially administered intravenously [41].

\subsubsection{Distribution}

The proinflammatory state of sepsis induces endothelial damage and increases capillary permeability [42]. This results in capillary leak syndrome, which causes fluid extravasation and increases the $V_{\mathrm{d}}$ of hydrophilic antibiotics [11]. Therapeutic interventions (e.g., fluid resuscitation, extracorporeal circuits, drainages) can also increase the 
$V_{\mathrm{d}}[43,44]$. Hypalbuminemia is also common in patients with sepsis, resulting in lower PB and higher unbound drug concentrations subject to increased clearance. These higher unbound drug concentrations may influence the $V_{\mathrm{d}}$, leading to subtherapeutic antibiotic concentrations and ineffective microbial clearance [45-47]. Inadequate tissue perfusion and tissue hypoxia are typical of critically ill patients, with both low and high oxygenation and perfusion areas [48].

\subsubsection{Metabolism}

Decreased hepatic blood flow, hepatic dysfunction, and altered enzyme activity impair metabolism in critically ill patients [49]. Tissue metabolism is also impaired by the decreased tissue blood flow and hypothermia [50]. Lipophilic antimicrobials may require dose adjustment in patients with hepatic failure since they are usually highly metabolized [47].

\subsubsection{Excretion}

The elimination process can be disturbed during critical illness, as renal clearance can be either enhanced or impaired. Biliary excretion is usually less impaired but can be affected by biliary stasis and a decreased gut transit leading to recirculation. Some critically ill patients have vasodilatation followed by a hyperdynamic cardiovascular state and therefore develop an augmented glomerular filtration rate (GFR), enhanced by the use of resuscitation fluid and vasopressors. This augmented renal clearance leads to increased elimination of hydrophilic drugs $[51,52]$. This may lead to underdosage, as demonstrated in a study with $\beta$-lactams [53]. On the other hand, some critically ill patients have acute kidney injury (AKI) and need renal replacement therapy (RRT) [54, 55]. This will result in decreased antimicrobial clearance of hydrophilic antibiotics, prolonged half-life, and potential toxicity [53]. Therefore, when AKI or RRT are present, dose adjustments should be considered.

\subsection{Sepsis Biomarkers}

Given the complexity of the host response in sepsis, some biomarkers may or may not predict these pharmacokinetic changes in the critically ill (Fig. 3). A biomarker is a quantifiable biological parameter that indicates a biological, pathogenic, or pharmacological response to exposure or therapeutic intervention. The ideal biomarker must be specific, sensitive, predictive, fast, cost effective, stable in vivo and in vitro, noninvasive, and sufficiently preclinically and clinically relevant [56]. Biomarkers are valuable because they generally occur earlier than clinical outcomes and are measured by objective methods [57]. Patient-specific response biomarkers to infections represent an opportunity to monitor treatment response and predict alterations in drug target-site exposure and clinical outcomes.

Sepsis biomarkers can predict the severity of sepsis and the development of organ failure, differentiate the type or prognosis of infection, and assess the response to treatment. However, the role of biomarkers in guiding antibiotic dosing has not yet been deeply evaluated [58]. Research on procalcitonin stewardship has been conducted, but other biomarkers may outperform it $[59,60]$. We have classified the potential biomarker predictors of pharmacokinetics according to pathophysiology: inflammation, endotheliopathy, coagulation, blood flow, and hepatic and renal function (Table 5). The diagnostic, prognostic, or therapeutic value of some of these biomarkers has been demonstrated, whereas the impact on drug pharmacokinetics is insufficiently understood. Table 5 displays the important biomarker characteristics. Knowledge of the biomarker's molecular weight (MW) is important to determine their reliability during extracorporeal therapies [61]. Comprehension of biomarker kinetics is essential because pathophysiological processes are continuously changing, and delayed dynamics may lead to delayed clinical decisions.

\subsubsection{Inflammation Biomarkers}

Sepsis is a "cytokine storm" syndrome. During infections, pathogen-associated molecular patterns such as lipopolysaccharide or peptidoglycan bind to pattern-recognizing receptors (PRRs) such as toll-like receptors, potentiated by the CD14 receptors. The immune system might respond to the pathogen with an exaggerated, uncontrolled, and massive release of proinflammatory cytokines such as interleukin (IL)-1 $\beta$, IL-6, IL-18; interferon, and tumor necrosis factor- $\alpha$ [42]. This increase in cytokines results in the continuous activation and expansion of immune cells from circulation to the infection. Proinflammatory cytokines also mediate the production of acute-phase reactants (APRs) by the liver [62, 63]. Some crucial APRs, such as C-reactive protein or procalcitonin, are routinely available for the identification and monitoring of inflammatory states [64, 65]. Conversely, the negative APRs, such as albumin and transferrin, decrease in response to inflammation [66].

This overwhelming inflammatory response correlates with capillary leakage, tissue edema, organ failure, and shock that causes the pharmacokinetic variability and changed plasma-to-tissue equilibration in sepsis. For example, IL-6, presepsin (sCD14 subtype), proadrenomedullin, and soluble triggering expressed receptor on myeloid cells (sTREM) have proven to be helpful biomarkers for the early diagnosis and prognosis of sepsis [67-71]. Some of these innovative biomarkers seem to be superior to the routinely used procalcitonin or C-reactive protein [72-74], so combinations of biomarkers have been proposed to increase 

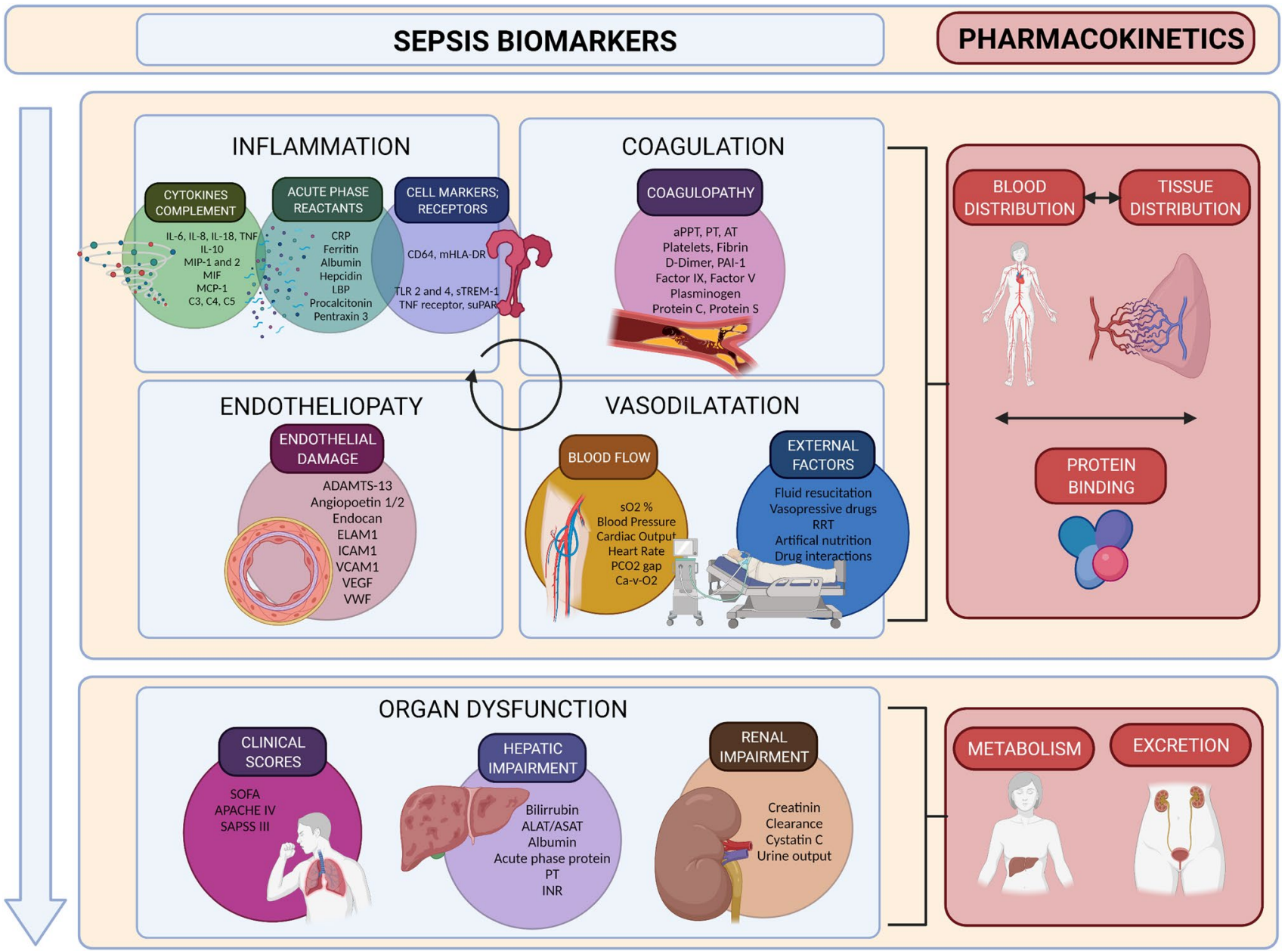

Fig. 3 Biomarkers that predict tissue pharmacokinetics in sepsis. The potential biomarkers and host factor predictors of pharmacokinetics are classified according to the different systems activated in sepsis: Changes in distribution (blood and tissue), metabolism, and excretion. Biomarkers representing each type of pathophysiological alteration might be able to predict the inter and intra-pharmacokinetic variability. ADAMTS-13 a disintegrin-like and metalloprotease with thrombospondin type 1 motif no. 13, ALAT alanine amino transferase, APACHE IV Acute Physiology and Chronic Health Evaluation-IV, $a P P T$ activated partial thromboplastin time, ASAT aspartate amino transferase, $A T$ antithrombin, $\mathrm{Ca}-\mathrm{V}-\mathrm{O}_{2}$ oxygen content difference, arterial-venous, $C R P$ C-reactive protein, ELAM endothelial leukocyte adhesion molecule, ICAM intercellular adhesion molecule, $I L$ interleukin, INR international normalized ratio, $L B P$ lipopolysaccharidebinding protein, $M C P$ monocyte chemoattractant protein, $m H L A$ monocytic human leukocyte antigen, $M I F$ migration inhibitory factor, $M I P$ macrophage inflammatory protein, $P A I$ plasminogen activator inhibitor, $\mathrm{PCO}_{2}$ partial pressure of carbon dioxide, $P T$ prothrombin time, $R R T$ renal replacement therapy, SAPSS III Simplified Acute Physiology Score-III, $\mathrm{SO}_{2}$ oxygen saturation, SOFA Sequential [Sepsis-related] Organ Failure Assessment, sTREM soluble triggering receptor expressed on myeloid cells 1, TLR toll-like receptor, TNF tumor necrosis factor, VCAM vascular cell adhesion molecule, VEGF vascular endothelial growth factor, $v W f$ von Willebrand factor sensitivity and specificity [75, 76]. Immunological biomarkers have been found to be indicative of effective antimicrobial therapy [77]. They are also promoters of the pathophysiological changes leading to pharmacokinetic variability in critically ill patients [78]. Accordingly, the immunological cells, cytokines, cell markers, and APRs may be potential biomarkers for predicting the tissue penetration and pharmacokinetics of antibiotics. The extent to which these inflammation molecules alter the PK/PD of antibiotics is unclear [79], but some of these molecules have already been successfully used to guide antibiotic treatment [59].

\subsubsection{Endothelial Biomarkers}

Inflammation, complement activation, and coagulation in sepsis induce severe impairment of endothelial functions. Endothelial cells are essential for hemostasis regulation, vasomotor control, and immune functions and form the vascular barrier for solute transport and osmotic balance [80-82]. Sepsis is associated with glycocalyx degradation and severe endothelial cell dysfunction, leading to dysregulation of hemostasis and vascular reactivity, as well as tissue edema [83]. This endotheliopathy results in excessive 
Table 5 Selected biomarkers for predicting antibiotic pharmacokinetics

\begin{tabular}{|c|c|c|c|c|c|c|c|}
\hline Biomarkers & Pathogenesis & Value & MW (kDa) & Peak (h) & $t_{1 / 2}^{\mathrm{a}}$ & $\begin{array}{l}\text { Affected } \\
\text { drug PK }\end{array}$ & References \\
\hline \multicolumn{8}{|c|}{ Inflammation biomarkers } \\
\hline \multicolumn{8}{|c|}{ Cytokines/chemokines } \\
\hline IL-1 $\beta$ & Proinflammatory cytokine & Px & $18-25$ & 4 & 2 & $\mathrm{D}$ & {$[227]$} \\
\hline IL-6 & Proinflammatory cytokine & $\mathrm{Dx}, \mathrm{Px}$ & 21 & 6 & $2-4$ & $\mathrm{D}$ & {$[228,229]$} \\
\hline IL-8 & Neutrophilic inflammation cytokine & $\mathrm{Dx}, \mathrm{Px}$ & 8.4 & $4-8$ & 4 & $\mathrm{D}$ & {$[230,231]$} \\
\hline IL-10 & Regulatory cytokine & Dx, Px & 18 & $12-24$ & $2-4$ & $\mathrm{D}$ & [232] \\
\hline $\mathrm{TNF} \alpha$ & $\begin{array}{l}\text { Proinflammatory cytokine, neutro- } \\
\text { philic activation }\end{array}$ & Px & 17.3 & 6 & $1-2$ & $\mathrm{D}$ & {$[233]$} \\
\hline $\mathrm{IFN} \gamma$ & $\mathrm{Th}_{1}$ immune response & - & 17 & 6 & 2 & $\mathrm{D}$ & {$[234,235]$} \\
\hline MIP-1, -2 & Neutrophil, leukocyte activation & $\mathrm{Px}$ & 440 & 2 & 2.5 & $\mathrm{D}$ & {$[236,237]$} \\
\hline MCP-1 & Monocyte chemoattractant protein & Px & & & & & {$[238]$} \\
\hline \multicolumn{8}{|c|}{ Cell markers/soluble receptors } \\
\hline Presepsin & $\begin{array}{l}\text { N-terminal fragment of sCD14 (LPS } \\
\text { receptor) }\end{array}$ & $\mathrm{Dx}, \mathrm{Px}, \mathrm{Tx}$ & 13 & 3 & $4-5$ & $\mathrm{D}$ & {$[239-241]$} \\
\hline CD64 & $\begin{array}{l}\text { Binds } \mathrm{Fc} \text { fraction of } \mathrm{IgG} \text {, induces } \\
\text { phagocytosis }\end{array}$ & $\mathrm{Dx}, \mathrm{Tx}$ & 43 & $4-6$ & $5-17$ & $\mathrm{D}$ & {$[242-244]$} \\
\hline mHLA-DR & $\begin{array}{l}\text { Expressed on APC, activation of } \\
\text { T-cells }\end{array}$ & Px & - & 24 & $3-22$ & $\mathrm{D}$ & {$[245,246]$} \\
\hline TLR2, TLR4 & $\begin{array}{l}\text { Recognition of bacterial peptidogly- } \\
\text { can (TLR2) or LPS (TLR4) }\end{array}$ & Dx & - & - & 3 & $\mathrm{D}$ & [247-249] \\
\hline sTREM-1 & TREM-1 secreted by phagocytes & Dx, Px & 23.8 & 6 & 1.5 & $\mathrm{D}$ & [250-252] \\
\hline SuPAR & $\begin{array}{l}\text { Recruitment of neutrophils and } \\
\text { monocytes }\end{array}$ & $\mathrm{Dx}, \mathrm{Px}$ & - & $4(d)$ & $10(d)$ & $\mathrm{D}$ & {$[253-255]$} \\
\hline \multicolumn{8}{|c|}{ Acute-phase reactants } \\
\hline CRP & $\begin{array}{l}\text { Complement activation, proinflam- } \\
\text { matory effects }\end{array}$ & Px & $20-25$ & $24-48$ & 19 & $\mathrm{D}$ & {$[256,257]$} \\
\hline PCT & $\begin{array}{l}\text { Prohormone stimulated by IL-1, } \\
\text { IL-6, TNF } \alpha\end{array}$ & $\mathrm{Dx}, \mathrm{Px}, \mathrm{Tx}$ & 14.5 & $6-24$ & $20-36$ & $\mathrm{D}$ & {$[258,259]$} \\
\hline LBP & Connects CD14 to bacteria LPS & Dx, Px & 50 & 12 & $12-24$ & $\mathrm{D}$ & {$[260]$} \\
\hline Pro-ADM & $\begin{array}{l}\text { Precursor of adrenomedullin, } \\
\text { induces vasodilatation }\end{array}$ & $\mathrm{Px}$ & $4-5.5$ & 4 & 2 & $\mathrm{D}$ & {$[261-263]$} \\
\hline Pentraxin 3 & Pathogen recognition and removal & $\mathrm{Dx}, \mathrm{Px}$ & 35 & - & 4 & $\mathrm{D}$ & {$[264-266]$} \\
\hline $\mathrm{C} 5 \mathrm{a}, \mathrm{C} 3 \mathrm{a}$ & Neutrophil migration, coagulopathy & $\mathrm{Dx}, \mathrm{Px}$ & 190 & - & 4 & $\mathrm{D}$ & {$[267,268]$} \\
\hline Albumin & Increased vascular permeability & $\mathrm{Px}$ & 66.5 & NA & $21(\mathrm{~d})$ & $\mathrm{D}, \mathrm{M}$ & {$[269-271]$} \\
\hline \multicolumn{8}{|c|}{ Endotheliopathy biomarkers } \\
\hline Syndecans & $\begin{array}{l}\text { Glycocalyx component indicates } \\
\text { damage }\end{array}$ & Px & 30 & NA & 0.06 & $\mathrm{D}$ & [272] \\
\hline Heparan sulfate & Polysaccharide & Px & 30 & NA & $3-4$ & $\mathrm{D}$ & [273] \\
\hline Endocan & $\begin{array}{l}\text { Soluble endothelial peptidoglycan, } \\
\text { increases microvascular perme- } \\
\text { ability }\end{array}$ & Px & 50 & NA & - & $\mathrm{D}$ & {$[94,274,275]$} \\
\hline Ang-2/Ang-1 & $\begin{array}{l}\text { Vascular integrity, Ang-2 is Ang-1 } \\
\text { antagonist }\end{array}$ & Px & 1 & NA & $30(s)$ & $\mathrm{D}$ & {$[99,254,276,277]$} \\
\hline sVCAM-1 & $\begin{array}{l}\text { Adhesion protein expressed by } \\
\text { endothelial cells, which binds to } \\
\text { lymphocytes }\end{array}$ & Px & 102 & NA & 4 & $\mathrm{D}$ & {$[278,279]$} \\
\hline sICAM-1 & Intercellular adhesion molecules & $\mathrm{Dx}, \mathrm{Px}$ & $76-114$ & NA & - & $\mathrm{D}$ & {$[278-281]$} \\
\hline E-selectin & $\begin{array}{l}\text { Glycoprotein expressed in activated } \\
\text { endothelial cells }\end{array}$ & $\mathrm{Px}$ & 115 & NA & 1.9 & $\mathrm{D}$ & {$[279,281,282]$} \\
\hline P-selectin & $\begin{array}{l}\text { Adhesion receptor expressed in } \\
\text { platelets and endothelial cell }\end{array}$ & Px & 140 & NA & 2.3 & $\mathrm{D}$ & [283] \\
\hline VEGF & Endothelial cells proliferation factor & Px & 23 & NA & $0.5-1$ & $\mathrm{D}$ & [284] \\
\hline \multicolumn{8}{|c|}{ Blood flow biomarkers } \\
\hline $\mathrm{SO}_{2} \%$ & Oxygen saturation & $\mathrm{Px}$ & NA & NA & NA & $\mathrm{D}$ & {$[285]$} \\
\hline MAP & Main global perfusion index & Px & NA & NA & NA & $\mathrm{D}$ & {$[286,287]$} \\
\hline $\mathrm{CO}$ & Cardiac output & Px & NA & NA & NA & $\mathrm{D}$ & [288] \\
\hline
\end{tabular}


Table 5 (continued)

\begin{tabular}{|c|c|c|c|c|c|c|c|}
\hline Biomarkers & Pathogenesis & Value & MW (kDa) & Peak (h) & $t_{1 / 2} \mathrm{a}^{\mathrm{a}}$ & $\begin{array}{l}\text { Affected } \\
\text { drug PK }\end{array}$ & References \\
\hline $\mathrm{HR}$ & Heart rate & Px & NA & NA & NA & $\mathrm{D}$ & [289] \\
\hline $\mathrm{ScvO}_{2}$ & Central venous oxygen saturation & Px & NA & NA & NA & $\mathrm{D}$ & [290] \\
\hline $\mathrm{StO}_{2}$ & Tissue oxygen saturation & Px & NA & NA & NA & $\mathrm{D}$ & [291] \\
\hline Lactate & Anaerobic glycolysis end product & Px & 0.08 & - & $20(\mathrm{~m})$ & $\mathrm{D}$ & [286] \\
\hline \multicolumn{8}{|l|}{ Coagulation biomarkers } \\
\hline vWf Ag & Platelet adhesion and accumulation & Px & $5000-10,000$ & NA & $4-26$ & $\mathrm{D}, \mathrm{M}$ & [292] \\
\hline ADAMTS-13 activity & $\mathrm{vWf}$ cleaving protease & Px & 154 & NA & $48-72$ & $\mathrm{D}, \mathrm{M}$ & [293-295] \\
\hline F ibrinogen & $\begin{array}{l}\text { Low activation of secondary } \\
\text { fibrinolysis }\end{array}$ & Px & 340 & NA & 100 & $\mathrm{D}, \mathrm{M}$ & {$[296,297]$} \\
\hline PT & $\begin{array}{l}\text { Consumption, depletion of endog- } \\
\text { enous haemostasis factors }\end{array}$ & Px & NA & NA & - & $\mathrm{D}, \mathrm{M}$ & {$[298,299]$} \\
\hline aPPT & Indicative of CRP activity & Dx & NA & NA & - & $\mathrm{D}, \mathrm{M}$ & [300-303] \\
\hline AT activity & $\begin{array}{l}\text { Coagulation inhibition and anti- } \\
\text { inflammation }\end{array}$ & Px & 58 & NA & 72 & $\mathrm{D}, \mathrm{M}$ & [296] \\
\hline PF-4 & $\begin{array}{l}\text { Protein secreted by activated } \\
\text { platelets }\end{array}$ & Px & 29 & NA & & $\mathrm{D}$ & [304-306] \\
\hline D-Dimer & $\begin{array}{l}\text { Fibrinogen, fibrin breakdown, exces- } \\
\text { sive coagulation }\end{array}$ & Px & 180 & NA & 8 & $\mathrm{D}, \mathrm{M}$ & [304] \\
\hline PAI-1 & Fibrinolysis inhibition & Px & 43 & NA & 2 & $\mathrm{D}$ & {$[304,307]$} \\
\hline Protein $\mathrm{C}$ & Antithrombotic action & Dx, Px & 62 & NA & 8 & $\mathrm{D}, \mathrm{M}$ & {$[308-310]$} \\
\hline Thrombomodulin & $\begin{array}{l}\text { Endothelial cells glycoprotein, } \\
\text { protein C pathway }\end{array}$ & Px & 74 & NA & 20 & $\mathrm{D}, \mathrm{M}$ & {$[311-313]$} \\
\hline \multicolumn{8}{|c|}{ Hepatic function biomarkers } \\
\hline Bilirubin & Product of heme catabolism & $\mathrm{Px}$ & 548.67 & NA & $2-4$ & $\mathrm{M}$ & [314-316] \\
\hline ALT & $\begin{array}{l}\text { Transaminase enzyme, indicates } \\
\text { liver function }\end{array}$ & - & 110 & NA & 8 & $\mathrm{M}$ & {$[316,317]$} \\
\hline AST & $\begin{array}{l}\text { Transaminase enzyme, indicates } \\
\text { liver function }\end{array}$ & - & 90 & NA & 16 & M & {$[316,317]$} \\
\hline Ceruloplasmin & $\begin{array}{l}\text { Increases as part of acute-phase } \\
\text { response }\end{array}$ & Px & 115 & - & 15 & M & [318] \\
\hline Hyaluronic acid & Indicates liver dysfunction & Px & $1000-8000$ & NA & $4(\mathrm{~m})$ & $\mathrm{D}, \mathrm{M}$ & [319] \\
\hline \multicolumn{8}{|l|}{ Renal function biomarkers } \\
\hline Creatinine & Estimate GFR & Px & 0.113 & NA & 3.85 & $\mathrm{E}$ & [320] \\
\hline Cystatin C & Estimate GFR & Px & 13.3 & NA & 2 & E & [320] \\
\hline BUN & $\begin{array}{l}\text { Urea nitrogen in blood, indicative of } \\
\text { renal function }\end{array}$ & Px & NA & NA & NA & $\mathrm{M}, \mathrm{E}$ & [321-323] \\
\hline NGAL & Indicative of kidney injury & Px & 25 & $6-12$ & 15 & E & {$[320,324]$} \\
\hline KIM-1 & Injured kidney epithelial cells & Px & $60-90$ & $12-24$ & 6 & $\mathrm{E}$ & [320] \\
\hline
\end{tabular}

The proposed biomarkers are classified according to the pathophysiological processes. We provide some important characteristics: pathogenesis, proved value, MW, biology (peak concentration, half-life), and the proposed pharmacokinetic process affected

ADAMTS-13 a disintegrin-like and metalloprotease with thrombospondin type 1 motif no, 13, ALT alanine transaminase, Ang angiotensin, $A P C$ activated protein C, $a P P T$ activated partial thromboplastin time, $A S T$ aspartate transaminase, $A T$ antithrombin, $B U N$ blood urea nitrogen, $C O$ cardiac output, $C R P$ C-reactive protein, $d$ days, $D$ distribution, $D x$ diagnostic, $E$ excretion, $G F R$ glomerular filtration rate, $H R$ heart rate, ICAM intercellular adhesion molecule $1, I F N$ interferon, $I g G$ immunoglobulin, $I L$ interleukin , $K I M-1$ kidney injury molecule-1, $L B P$ lipopolysaccharide-binding protein, $L P S$ lipopolysaccharide, $M$ metabolism, $m$ minutes, $M A P$ mean arterial pressure, $M C P$ monocyte chemoattractant protein, $m H L A$ monocytic human leukocyte antigen, $M I P$ macrophage inflammatory protein, $M W$ molecular weight, $N A$ not applicable, $N G A L$ Neutrophil Gelatinase-Associated Lipocalin, $P A I-1$ plasminogen activator inhibitor-1, $P C T$ procalcitonin, $P F-4$ platelet factor $4, P K$ pharmacokinetics, Pro-ADM proadrenomedullin, $P T$ prothrombin time, $P x$ prognostic, $s$ seconds, $s C D 14$ soluble cluster of differentiation $14, S c v O_{2}$ central venous oxygen saturation, $S I C A M$ soluble ICAM, $\mathrm{SO}_{2} \%$ oxygen saturation, $\mathrm{StO}_{2}$ tissue oxygen saturation, sTREM soluble triggering receptor expressed on myeloid cells 1 , suPAR soluble urokinase-type plasminogen activator receptor, $s V C A M$ soluble VCAM, $t_{1 / 2}$ elimination half-life, $T h_{l} \mathrm{~T}$ helper type 1, TLR toll-like receptor, $T N F$ tumor necrosis factor, $T x$ therapeutic, $V C A M$ vascular cell adhesion molecule, $V E G F$ vascular endothelial growth factor, $v W f$ von Willebrand factor

${ }^{\mathrm{a}} t_{1 / 2}$ presented in $\mathrm{h}$ unless otherwise indicated 
microvascular permeability to the extravascular space, leading to interstitial edema [84-86].

Glycocalyx degradation releases components such as syndecan-1 [87-89], heparan sulfate [90], and hyaluronan $[91,92]$ into the plasma. Endocan is expressed in human endothelial cells in response to proinflammatory cytokines and increases microvascular permeability [93-95]. These endothelial glycocalyx biomarkers have already been presented as predictors of death and/or organ dysfunction during sepsis. The angiopoietin protein family has been investigated as a critical mediator of glycocalyx degradation since angiopoietin-2-activated endothelial cells increase the expression of intercellular adhesion molecule-1 and vascular cell adhesion molecule-1 [96, 97]. As a result, endothelial cell-cell junctions alter, resulting in microvascular leak. The angiopoietin-2/1 ratio has been found to be a good predictor of 28-day mortality in patients with sepsis [98-100]. Serum vascular endothelial growth factor and its receptor stimulate endothelial growth, proliferation, and permeability. Higher levels can be found in sepsis and so can be used for prognosis [101]. Therefore, these endotheliopathy biomarkers are predictors of the capillary leakage that drives the pharmacokinetic variability in tissues of patients with sepsis, yet the extent of the relevance needs to be established for the individual markers.

\subsubsection{Coagulation Biomarkers}

Coagulopathy and disseminated intravascular coagulation (DIC) are common defense mechanisms in critically ill patients [102]. Coagulopathy consists of microvascular thrombosis and consumption of platelets and coagulation proteins, eventually causing bleeding [103]. DIC is a microvascular thrombosis leading to bleeding and organ dysfunction, leading to amplified coagulopathy. Although the formation of microthrombi might prevent microorganisms from accessing tissue, it also further enhances tissue ischemia and organ damage, contributing to decreased antibiotic distribution [103]. However, it can also lead to capillary leakage, promoting an increase in tissue permeability [104]. Coagulopathy is also the hallmark of liver failure, an organ with a central role in clotting [105]. Different coagulation phenotypes in sepsis have been described, with two sepsis subgroups showing severe disease and coagulopathy [106].

Various significant players drive the pathogenesis of coagulopathy in sepsis: platelets, the coagulation system, the endothelium, and the immune system [107]. In sepsis, procoagulant mechanisms are upregulated while natural anticoagulants are simultaneously downregulated. Tissue factor activates the coagulation cascade (including Factor VII, Factor X, thrombin, and fibrin) and is amplified by proinflammatory cytokines. Sepsis inflammation response also activates platelet activating factor and thrombin-induced exocytosis of P-selectin and von Willebrand factor (vWf). As a result, platelets adhere, activate, and aggregate, leading to microvascular obstruction. Cell receptors and adhesive proteins, such as vWf and fibrinogen, mediate this interaction between platelets and the vessel wall [108]. Thrombogenesis is accelerated when the ADAMTS (a disintegrin and metalloproteinase with thrombospondin motifs)-13 protease is consumed and cannot cleave the excessive amount of large vWf polymers [109], and the microthrombosis leads to thrombocytopenia. The inflammatory response impairs the three central anticoagulant mechanisms: tissue factor pathway inhibitor, antithrombin, and activated protein $\mathrm{C}$. Tissue factor pathway inhibitor is decreased in sepsis because of degradation by proteolytic enzymes produced by the host, such as plasmin [110]. Another essential anticoagulant protein is antithrombin. Most of these coagulation biomarkers have been related to a worse prognosis: thrombomodulin [111, 112], plasminogen activator inhibitor 1 [113], vWf [114-116], ADAMTS-13 [116-118], and thrombocytopenia $[119,120]$. A prolonged coagulation time is frequent in critically ill patients, and prothrombin time and activated partial thromboplastin time have been found to be predictors of sepsis and mortality $[107,121]$. Hemolysis (free hemoglobin) [122] and D-dimers (excessive coagulation activation) [107, 123] have also been demonstrated as survival predictors. Scoring systems such as sepsis-induced coagulopathy [124] and Overt-DIC scoring systems [125] have been described to predict coagulopathy in patients with associated disorders. A capillary leakage index using albumin and polymerase chain reaction has also been described as a prognosis marker [126]. Coagulation host factors indicative of tissue penetration may indicate changes in antibiotic tissue penetration. Therefore, both conventional and new molecular markers may be used to determine coagulopathy and optimize antibiotic dosing.

\subsubsection{Blood Flow Biomarkers}

Sepsis has variable effects on macro/microvascular blood flow, which might lead to simultaneous observation of vasoconstriction and vasodilatation [127]. Septic shock is characterized by derangement in global hemodynamic parameters, such as blood pressure (BP), cardiac output, and heart rate. Despite increased cardiac output, the tissues cannot utilize oxygen, as evidenced by high lactate levels, deranged acidbase balance, and increased $\mathrm{CO}_{2}$ levels [128]. This indicates that macrovascular tissue perfusion in severe sepsis is often uncoupled from systemic circulation [129]. This discrepancy between macro- and microcirculation of internal organs impedes effective hemodynamic monitoring of patients with sepsis [130].

The determination of macro/microvascular dysfunction can be a prognostic parameter and can guide therapeutic 
measures in patients with septic shock. We can use some objective markers of tissue perfusion to predict global tissue distribution. The main global perfusion index is mean arterial pressure, preferably systolic, as it better reflects organ perfusion. Oxygen saturation of mixed venous blood is another routinely used indicator of the balance between oxygen transport and consumption, since its decrease reflects a reduction in cardiac output [131]. Although tissue oxygen saturation, measured by tissue spectroscopy, is not routinely used, it has been found to correlate with central venous saturation [132] and cardiac index in patients with septic shock [133]. In addition, the need for vasopressors to maintain BP has indicated inadequate antibiotic penetration [24]. Hyperlactatemia is a common condition in patients with sepsis and may be indicative of changes in microvascular flow. Lactate is the anaerobic glycolysis product, and its blood levels increase significantly in hypoperfusion or hypoxia cases [134]. Lactate levels have been used to guide resuscitation, predict in-hospital mortality, and stratify patient risk [135, 136]. Moreover, lactate is one of the criteria for diagnosing septic shock, as indicated by Sepsis-3 criteria [137]. However, septic hyperlactatemia is not a straightforward indication of inadequate oxygen delivery [138]. Lactate overproduction is also a protective response to stress to allow cellular energy production to continue when tissue oxygen supply is inadequate for aerobic metabolism [139], and elevated levels of lactate can also be caused by a decreased clearance by the liver $[139,140]$. It is suggested that initially elevated lactate can indicate an adaptive response to a hypermetabolic state during sepsis [139]. Therefore, when assessing tissue perfusion, lactate should be combined with other markers. Finally, regional perfusion can also be assessed using indices of organ function, such as the SOFA (Sequential [Sepsis-related] Organ Failure Assessment) score. Other nonobjective indicators of tissue hypoperfusion are oliguria, impaired sensorium, delayed capillary refill, and skin coldness. All these blood flow markers might predict the vasodilatation or vasoconstriction that drives changes in drug $V_{\mathrm{d}}$, especially affecting hydrophilic antibiotics.

\subsubsection{Hepatic Function Biomarkers}

The liver has a significant role in sepsis response through clearance of pathogenic microorganisms, APRs, and release of liver-derived cytokines, inflammatory mediators, and coagulation cascade components. Of course, it also has a central role in all metabolic processes in the body [141, 142]. Remarkably, liver dysfunction is common in patients in the ICU and is found in at least one-third of patients with sepsis [143]. Hepatic malfunction results in impaired detoxification of drugs that are typically excreted in the bile because of phase I and II enzyme deficiency [144, 145]. It also contributes to stress hyperglycemia through increased hepatic output of glucose, decreased clearance of lactate, and increased metabolism of lipids, but cholesterol synthesis and turnover are impaired.

Deficiencies in fibrinolytic proteins, anticoagulant proteins, procoagulation factors, and protein synthesis, such as albumin, are often present in liver failure, in part due to failure of the synthesis and consumption. Hypoalbuminemia leads to alterations in $\mathrm{PB}$, which may increase the unbound drug fraction in high-PB drugs [146] as described in Sect. 4.1. However, ascites are typical of advanced liver disease and increase the $V_{\mathrm{d}}$ of hydrophilic antibiotics. Therefore, hepatic dysfunction may affect not only the metabolism of drugs but also their PB and $V_{\mathrm{d}}$, modifying antibiotic concentrations in the site of infection. These pharmacokinetic changes have been found in critically ill patients receiving meropenem, which required dosing modifications to reach target attainment [147].

Various liver dysfunction markers may serve as biomarkers for predicting pharmacokinetic variability. Bilirubin is the standard parameter for assessing hepatic failure, has been confirmed as an independent predictor of sepsis mortality [148], and is routinely checked with the SOFA score. The antimicrobial proteins, inflammatory mediators, and coagulation factors produced by the liver during acutephase response might also be considered as indicators of pharmacokinetic changes. Although these biomarkers lack the specificity for liver damage, they may be indicators of pathophysiological changes in drug metabolism, distribution, and clearance, which affects the penetration of antibiotics [149-152]. Recently, hyaluronic acid was proposed as an indicator of early liver impairment in critically ill patients and was identified as a particular risk for mortality in patients with infections [153]. The Child-Pugh score categorizes patients according to the severity of liver function impairment by incorporating five variables: serum bilirubin, serum albumin, prothrombin time, the presence of encephalopathy, and the presence of ascites. It is frequently used to assess the severity of liver function impairment but lacks the sensitivity to quantitate the specific ability of the liver to metabolize individual drugs [151]. Moreover, in patients in the ICU, the Child-Pugh score may be strongly influenced by hypoalbuminemia and thus not be optimal to identify hepatic impairment. However, it can be useful to identify pharmacokinetic changes, since hypoalbuminemia is relevant for altered pharmacokinetics (PB). The liver plays a central role in pharmacokinetic processes, so liver biomarker-guided dosing may be essential to identify at-risk patients and optimize treatment.

\subsubsection{Renal Function Biomarkers}

Renal injury is typical in the ICU and can be caused by ischemia, cellular hypoxia, inflammation, or toxic injury 
$[54,55]$. Many antibiotics are renally cleared or nephrotoxic; therefore, kidney disease or augmented renal clearance further complicate sepsis treatment as explained in Sect. 4.2.4. Alterations in renal function require careful consideration of drug dosing. Diagnosis of renal function usually relies on biomarkers determining the GFR, which is also used for monitoring and calculating drug dosage. The determination of GFR is based on the concept of clearance: renal clearance. If the marker has no extrarenal elimination, tubular reabsorption, or secretion, clearance is given by the formula GFR $=\mathrm{UV} / \mathrm{P}$, where $\mathrm{U}$ is the concentration of the marker in urine, $\mathrm{V}$ is the urine flow rate, and $\mathrm{P}$ is the concentration in plasma. Classic biomarkers to determine renal function are blood urea nitrogen, urine output, serum creatinine $(\mathrm{sCr})$, and urinary albumin [154-156]. sCr is the most common marker of renal function and has been used as a significant covariate in pharmacokinetic models for critically ill patients [157-159]. However, $\mathrm{sCr}$ is prone to error in patients with low muscle mass or fluid overload, which is a limitation. Furthermore, $\mathrm{sCr}$ or blood urea nitrogen levels change late after injury since there is a functional reserve. To overcome these limitations, novel biomarkers have been proposed. The correlation of cystatin C with GFR is superior to that of $\mathrm{sCr}$ and is not influenced by changes in muscle mass, which is important in hospitalization-associated myopathy [160-162]. Neutrophil gelatinase-associated lipocalin (NGAL) and kidney injury molecule-1 are innovative biomarkers specific to renal ischemia, which leads to renal failure [163, 164]. Moreover, NGAL appears to correlate with sepsis severity [165]. GFR is already used for individualized dosage adjustments since antimicrobial concentrations depend on the extent of renal function impairment. Hypoalbuminemia and altered renal clearance are pathophysiological processes that have a high prevalence in critically ill patients and lead to pharmacokinetic-related changes. Yet, the potential impact on tissue pharmacokinetics is yet to be established.

\subsubsection{Other Factors}

Other factors, including specific treatments, influence the underlying pathophysiological mechanisms and, therefore, pharmacokinetics.

Need for fluid resuscitation During sepsis, the body needs extra fluids to help keep the BP from dropping dangerously low and causing shock [166, 167]. However, it increases the $V_{\mathrm{d}}$, therefore affecting pharmacokinetics. Moreover, fluid resuscitation may significantly affect glycocalyx integrity via atrial natriuretic peptide release, leading to capillary leakage and drug distribution changes [168, 169].

Need for vasopressive drugs Vasopressor agents are used to increase BP and improve tissue perfusion. However, they may also impair cardiac output and preferentially vasoconstrict some vascular beds, particularly the skin and splanchnic area [170, 171]. Therefore, drug distribution and clearance might be impaired.

$R R T$ Extracorporeal support is often necessary for the critically ill population. However, this exchange of substances between the blood and other fluid via a semipermeable membrane alters $V_{\mathrm{d}}$ and PB and the excretion of the drug [172-175]. RRT leads to high pharmacokinetic variability [176], probably because of the residual organ function and the changes in dialysate flow rates. Therefore, dose adjustment may be indicated [175].

Obesity Lipophilicity is a significant determinant of a drug's $V_{\mathrm{d}}$. Patients with obesity have more lipophilic tissue than those included in standardized studies. Lipophilic drugs are associated with a higher $V_{\mathrm{d}}$ in patients with obesity, but the weight-related $V_{\mathrm{d}}$ of lipophilic drugs can be higher or lower in patients with obesity than in those without [177]. Therefore, adjustment of dose needs to be considered on a case-by-case base for different drugs.

\section{Biomarker-Guided Dosing}

Critically ill patients experience a range of these alterations in varying degrees of severity, which in turn, also varies over time. This results in intra- and interpatient variability in antibiotic concentration at the site of infection [7, 8]. A wide range of methods might be used to assess penetration at the target site in critically ill patients $[178,179]$, although they cannot be used routinely. Instead, we could strengthen antibiotic dosing strategies with biomarkers that correlate with pharmacokinetic alterations, since they might predict targetsite concentrations (Fig. 4). With model-informed precision dosing, clinical and microbiological elements might be used in pharmacometric models to optimize dosing in critically ill patients [180-183]. The identified biomarkers can be added to model-informed precision dosing [58] as covariates.

\subsection{Testing Methods}

An ideal biomarker should have a fast, widely available, and reliable determination method. However, it is challenging to obtain pure reference standards for specific biomarkers and also complex to validate analytical methods because of their heterogeneity. Some of the biomarkers proposed are routinely available, whereas some of the promising new ones might be more difficult to perform and validate. Recently, some of these new biomarkers have been tested in multiplex tests [184]. These tests simultaneously measure various biomarkers from the same biological sample with low sample volumes. Obviously, we need to harmonize and standardize the immunoassays before incorporating these biomarkers into clinical practice $[185,186]$. 


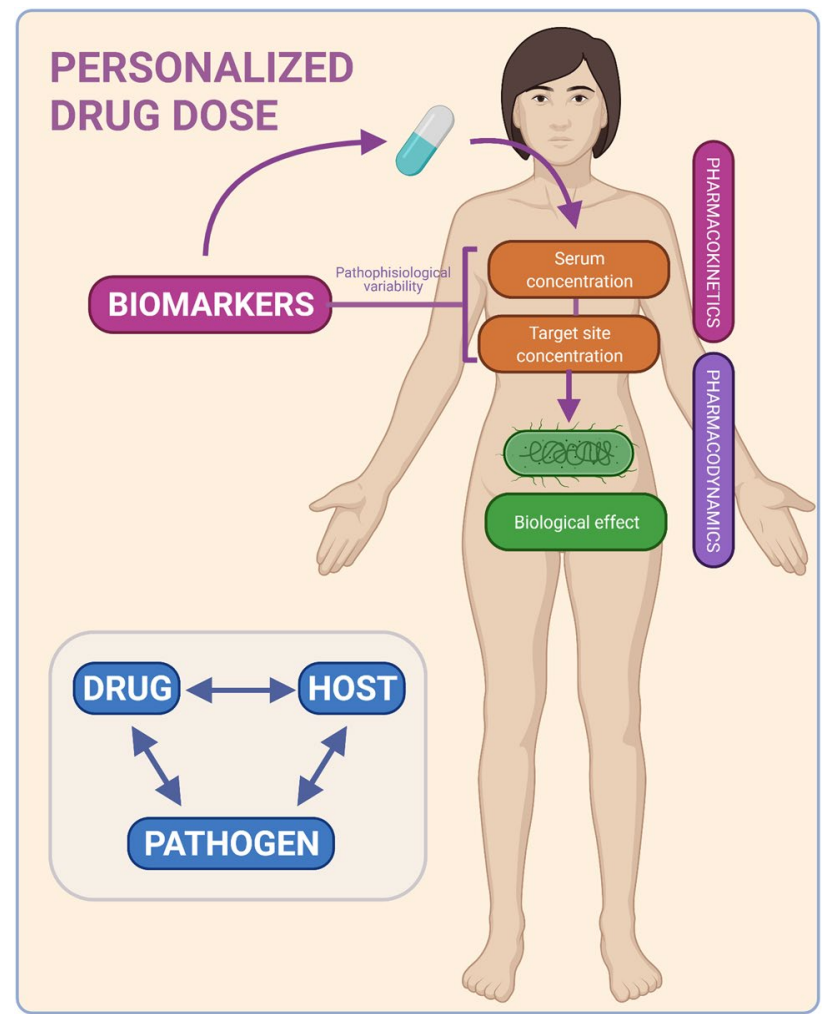

Fig. 4 Personalized antibiotic dosing. Antibiotic dosing strategies taken by physicians might be strengthened by the levels of biomarkers that reflect the drug pharmacokinetics

\subsection{Kinetics of Biomarkers}

In addition, sepsis is a rapidly changing condition. The precise time during which a biomarker is useful varies because of the substantial differences in their kinetics. An ideal biomarker should rapidly and specifically increase in sepsis, rapidly decrease after effective therapy, and have a short half life. None of the current biomarkers includes all of these specifications. Moreover, in most studies, biomarkers have not been measured repeatedly, and static threshold concentrations have been used to make clinical decisions [187]. This limits their use in antibiotic optimization as the variability must be assessed and controlled.

\subsection{Molecular Weight}

An increase in the use of extracorporeal therapies makes us consider whether RRT may remove these biomarkers. If so, we would need to consider the extent of this, depending on the biomarker MW and cut-off value of the membrane and RRT technique used [61].

\subsection{Combination of Biomarkers}

Sepsis is complex and heterogeneous, so no ideal single sepsis biomarker exists. The most effective way to optimize the treatment of sepsis is the combination of various sepsis biomarkers [188]. Over 258 biomarkers have been assessed for their use in sepsis [189], but none has shown sufficient specificity and sensitivity for routine use in clinical practice. Combining these biomarkers will reflect different aspects of the host response and help overcome the limitations of a single biomolecule for the prediction of the plasma and tissue pharmacokinetics of antibiotics [190].

\subsection{Missing Evidence}

Several biomarkers have been linked to diagnosis or prognosis, but few studies have evaluated their role in antibiotic stewardship. Therefore, prospective studies investigating the potential role of the expanding field of sepsis biomarkers for antimicrobial dose optimization are needed. Moreover, clinic-economic data to recommend its introduction into clinical practice effectively are lacking.

\subsection{Therapeutic Drug Monitoring}

TDM allows adjustment of the antibiotic dose based on the concentration measured in plasma. This tool can help with personalization and optimization of antibiotic doses [191]. However, it should be noted that no studies have yet demonstrated clinical improvements with TDM. Because the antibiotic concentration in the plasma is not always the same as that at the target site, the proposed biomarkers could be applied in TDM based on antibiotic concentrations at the site of infection, rather than in plasma.

\section{Critical Discussion}

Current evidence on biomarkers and pharmacokinetic optimization of antibiotics in the critically ill population is limited. There is evidence to demonstrate the failure of optimal PK/PD exposure in critically ill patients. However, robust data on how to predict a therapeutic effect based on antimicrobial exposure and how precision dosing improves patient outcomes are lacking. In recent years, many new sepsis biomarkers have emerged to improve and guide treatment. However, most of the biomarker studies have limited evidence, and their clinical significance has yet to be proven. The weak evidence of current studies may be due to the study design, sample size, risk of bias, and lack of validation. A biomarker must be able to guide treatment to be useful in clinical practice. Moreover, critically ill patients are a 
very heterogeneous population. Based on current knowledge and evidence, it is difficult to design a personalized dosing regimen.

With this review, we proposed and discussed how pharmacokinetic biomarker-guided therapy can optimize antibiotic exposure in critically ill patients. The association between hepatic and renal biomarkers and pharmacokinetics is clear. We now also propose inflammation, endothelial, coagulation, and blood flow markers to characterize this pharmacokinetic variability in critically ill patients. We link biomarkers and pharmacokinetic changes based on extrapolation of patient physiological changes during sepsis that lead to this pharmacokinetic variability. However, their association with altered pharmacokinetics and their clinical relevance still needs to be characterized. We therefore propose potential biomarkers to define antibiotic pharmacokinetics in sepsis as a research perspective to improve antibiotic treatment in the ICU.

\section{Conclusion}

Adequate antimicrobial dosing to achieve PK/PD targets in patients with sepsis remains a challenge because of changes in $V_{\mathrm{d}}$, clearance, and $\mathrm{PB}$. On top of changes in systemic plasma, exposure to the tissue-to-plasma ratio might differ from that in a healthier population. This review aimed to characterize sepsis biomarkers and propose how they can predict the target-site concentrations of antibiotics. We categorized the main drivers of altered tissue pharmacokinetics into inflammation, coagulopathy, endotheliopathy, and organ failure. These sepsis biomarkers might predict pharmacokinetic changes and target-site concentrations. However, clinical evidence, standardization, and threshold definitions for these biomarkers are currently lacking. We propose biomarker-based drug monitoring for dose optimization and encourage new lines of research in this direction. Future research should focus on the determination of in vivo plasma/tissue distribution, the study of sepsis biomarkers, and their correlation and clinical application.

Acknowledgements MSC thanks Sonia Luque Pardos and Jordi Rello Condomines for their advice.

\section{Declarations}

Funding Open access funding provided by Medical University of Vienna. This project received funding from the European Union's Horizon 2020 research and innovation program under the Marie Sklodowska-Curie Grant agreement no. 861323.

Conflicts of interest Maria Sanz Codina is a member of TIPAT (Training towards Innovative personalized Antibiotic Therapy), an Innovative Training Network for early-stage researchers. Maria Sanz Codina and Markus Zeitlinger have no conflicts of interest that are directly relevant to the content of this article.

Ethics approval Not applicable.

Consent to participate Not applicable.

Consent for publication Not applicable.

Availability of data and material Not applicable.

Code availability Not applicable.

Author contributions Maria Sanz Codina and Markus Zeitlinger both made substantial contributions to the conception, drafting, and critical revision of the manuscript for important intellectual content and approved the final version of the manuscript.

Open Access This article is licensed under a Creative Commons Attribution-NonCommercial 4.0 International License, which permits any non-commercial use, sharing, adaptation, distribution and reproduction in any medium or format, as long as you give appropriate credit to the original author(s) and the source, provide a link to the Creative Commons licence, and indicate if changes were made. The images or other third party material in this article are included in the article's Creative Commons licence, unless indicated otherwise in a credit line to the material. If material is not included in the article's Creative Commons licence and your intended use is not permitted by statutory regulation or exceeds the permitted use, you will need to obtain permission directly from the copyright holder. To view a copy of this licence, visit http://creativecommons.org/licenses/by-nc/4.0/.

\section{References}

1. Shankar-Hari M, Phillips GS, Levy ML, Seymour CW, Liu VX, Deutschman CS, et al. Developing a newdefinition and assessing newclinical criteria for Septic shock: For the third international consensus definitions for sepsis and septic shock (sepsis-3). JAMA J Am Med Assoc. 2016;315(8):775-87.

2. Rudd KE, Johnson SC, Agesa KM, Shackelford KA, Tsoi D, Kievlan DR, et al. Global, regional, and national sepsis incidence and mortality, 1990-2017: analysis for the Global Burden of Disease Study. Lancet. 2020;395(10219):200-11.

3. Reinhart K, Daniels R, Kissoon N, Machado FR, Schachter RD, Finfer S. Recognizing Sepsis as a Global Health Priority-a WHO Resolution Konrad. N Engl J Med. 2017;377(5):411-4.

4. Zhou F, Yu T, Du R, Fan G, Liu Y, Liu Z, et al. Clinical course and risk factors for mortality of adult inpatients with COVID19 in Wuhan, China: a retrospective cohort study. Lancet. 2020;395(10229):1054-62.

5. Rello J, Tejada S, Xu E, Solé-Lleonart C, Campogiani L, Koulenti D, et al. Quality of evidence supporting surviving sepsis campaign recommendations. Anaesth Crit care pain Med. 2020;39(4):497-502.

6. Micek ST, Heard KM, Gowan M, Kollef MH. Identifying critically ill patients at risk for inappropriate antibiotic therapy: A pilot study of a point-of-care decision support alert. Crit Care Med. 2014:42(8):1832-8.

7. Mouton JW, Theuretzbacher U, Craig WA, Tulkens PM, Derendorf $\mathrm{H}$, Cars O. Tissue concentrations: do we ever learn? J Antimicrob Chemother. 2008;61(2):235-7.

8. Blot S, Koulenti D, Akova M, Bassetti M, De Waele JJ, Dimopoulos $\mathrm{G}$, et al. Does contemporary vancomycin dosing achieve 
therapeutic targets in a heterogeneous clinical cohort of critically ill patients? Data from the multinational DALI study. Crit Care. 2014;18(3):1-11.

9. Rello J, Valenzuela-Sánchez F, Ruiz-Rodriguez M, Moyano S. Sepsis: a review of advances in management. Adv Ther. 2017;34(11):2393-411.

10. Roberts JA, Abdul-Aziz MH, Lipman J, Mouton JW, Vinks AA, Felton TW, et al. Individualised antibiotic dosing for patients who are critically ill: Challenges and potential solutions. Lancet Infect Dis. 2014;14(6):498-509.

11. Blot SI, Pea F, Lipman J. The effect of pathophysiology on pharmacokinetics in the critically ill patient-concepts appraised by the example of antimicrobial agents. Adv Drug Deliv Rev. 2014;77:3-11.

12. Weier N, Nathwani D, Thursky K, Tängdén T, VlahovićPalčevski V, Dyar O, et al. An international inventory of antimicrobial stewardship (AMS) training programmes for AMS teams. J Antimicrob Chemother. 2021;76(6):1633-40.

13. Maraolo AE, Ong DSY, Cimen C, Howard P, Kofteridis DP, Schouten J, et al. Organization and training at national level of antimicrobial stewardship and infection control activities in Europe: an ESCMID cross-sectional survey. Eur J Clin Microbiol Infect Dis Off Publ Eur Soc Clin Microbiol. 2019;38(11):2061-8.

14. Sandiumenge A, Diaz E, Bodí M, Rello J. Therapy of ventilator-associated pneumonia: a patient-based approach based on the ten rules of "The Tarragona Strategy." Intensive Care Med. 2003;29(6):876-83.

15. Wallenburg E, ter Heine R, Schouten JA, Brüggemann RJM. Personalised antimicrobial dosing: standing on the shoulders of giants. Int J Antimicrob Agents. 2020;56(3).

16. Rello J, Perez A. Precision medicine for the treatment of severe pneumonia in intensive care. Expert Rev Respir Med. 2016;10(3):297-316.

17. Chua HC, Tse A, Smith NM, Mergenhagen KA, Cha R, Tsuji BT. Combatting the rising tide of antimicrobial resistance: pharmacokinetic/pharmacodynamic dosing strategies for maximal precision. Int J Antimicrob Agents. 2021;57(3):106269.

18. Chai MG, Cotta MO, Abdul-Aziz MH, Roberts JA. What are the current approaches to optimising antimicrobial dosing in the intensive care unit? Pharmaceutics. 2020;12(7):1-22.

19. Minichmayr IK, Roberts JA, Frey OR, Roehr AC, Kloft C, Brinkmann A. Development of a dosing nomogram for continuousinfusion meropenem in critically ill patients based on a validated population pharmacokinetic model. J Antimicrob Chemother. 2018;73(5):1330-9.

20. Muller M, Pena A, Derendorf H. MINIREVIEW-issues in pharmacokinetics and pharmacodynamics of anti-infective agents: distribution in tissue. Agents. 2004;48(5):1441-53.

21. Ljungström L, Pernestig AK, Jacobsson G, Andersson R, Usener B, Tilevik D. Diagnostic accuracy of procalcitonin, neutrophillymphocyte count ratio, $\mathrm{C}$-reactive protein, and lactate in patients with suspected bacterial sepsis. PLoS ONE. 2017; 12.

22. Yeh CF, Wu CC, Liu SH, Chen KF. Comparison of the accuracy of neutrophil $\mathrm{CD} 64$, procalcitonin, and $\mathrm{C}$-reactive protein for sepsis identification: a systematic review and meta-analysis. Ann Intensive Care. 2019;9(1):5. https://doi.org/10.1186/ s13613-018-0479-2.

23. Póvoa P, Salluh JIF. Biomarker-guided antibiotic therapy in adult critically ill patients: A critical review. Ann Intensive Care. 2012;2(1):32. https://doi.org/10.1186/2110-5820-2-32.

24. Zeitlinger BS, Zeitlinger M, Leitner I, Müller M, Joukhadar C. Clinical scoring system for the prediction of target site penetration of antimicrobials in patients with sepsis. Clin Pharmacokinet. 2007;46(1):75-83.

25. Pea F. Plasma pharmacokinetics of antimicrobial agents in critically ill patients. Curr Clin Pharmacol. 2013;8(1):5-12.
26. Roberts JA, Lipman J. Pharmacokinetic issues for antibiotics in the critically ill patient. Crit Care Med. 2009;37(3):840-51.

27. Zeitlinger MA, Sauermann R, Traunmüller F, Georgopoulos A, Müller M, Joukhadar C. Impact of plasma protein binding on antimicrobial activity using time-killing curves. J Antimicrob Chemother. 2004;54(5):876-80.

28. Jorda A, Zeitlinger M. Preclinical pharmacokinetic/pharmacodynamic studies and clinical trials in the drug development process of EMA-approved antibacterial agents: a review. Clin Pharmacokinet. 2020;59(9):1071-84.

29. Roberts JA, Abdul-Aziz MH, Davis JS, Dulhunty JM, Cotta MO, Myburgh J, et al. Continuous versus intermittent $\beta$-lactam infusion in severe sepsis: A meta-analysis of individual patient data from randomized trials. Am J Respir Crit Care Med. 2016;194(6):681-91.

30. Drusano GL, Ambrose PG, Bhavnani SM, Bertino JS, Nafziger AN, Louie A. Back to the future: using aminoglycosides again and how to dose them optimally. Clin Infect Dis an Off Publ Infect Dis Soc Am. 2007;45(6):753-60.

31. Baptista PP, Roberts JA, Sousa E, Freitas R, Deveza N, Pimentel J. Decreasing the time to achieve therapeutic vancomycin concentrations in critically ill patients: Developing and testing of a dosing nomogram. Crit Care. 2014;18(1):1-9.

32. Nicolau DP. Optimizing outcomes with antimicrobial therapy through pharmacodynamic profiling. J Infect Chemother Off J Japan Soc Chemother. 2003;9(4):292-6.

33. Kumar A, Ellis P, Arabi Y, Roberts D, Light B, Parrillo JE, et al. Initiation of inappropriate antimicrobial therapy results in a fivefold reduction of survival in human septic shock. Chest. 2009;136(5):1237-48.

34. Hanberger H, Antonelli M, Holmbom M, Lipman J, Pickkers P, Leone $\mathrm{M}$, et al. Infections, antibiotic treatment and mortality in patients admitted to ICUs in countries considered to have high levels of antibiotic resistance compared to those with low levels. BMC Infect Dis. 2014;14(1):1-9.

35. Gonçalves-Pereira J, Póvoa P. Antibiotics in critically ill patients: A systematic review of the pharmacokinetics of $\beta$-lactams. Crit Care. 2011;15(5):R206.

36. Abdulla A, Dijkstra A, Hunfeld NGM, Endeman H, Bahmany $\mathrm{S}$, Ewoldt TMJ, et al. Failure of target attainment of betalactam antibiotics in critically ill patients and associated risk factors: A two-center prospective study (EXPAT). Crit Care. 2020;24(1):1-12.

37. Wiersinga WJ, Leopold SJ, Cranendonk DR, van der Poll T. Host innate immune responses to sepsis. Virulence. 2014;5(1):36-44.

38. Lambden S, Creagh-Brown BC, Hunt J, Summers C, Forni LG. Definitions and pathophysiology of vasoplegic shock. Crit Care. 2018;22:174. https://doi.org/10.1186/s13054-018-2102-1.

39. Hotchkiss RS, Monneret G, Payen D. Sepsis-induced immunosuppression: from cellular dysfunctions to immunotherapy. Nat Rev Immunol. 2013;13(12):862-74.

40. Delano MJ, Ward PA. The immune system's role in sepsis progression, resolution, and long-term outcome. Immunol Rev. 2016;274(1):330-53.

41. Charlton M, Thompson JP. Pharmacokinetics in sepsis. BJA Educ. 2019;19(1):7-13.

42. Chousterman BG, Swirski FK, Weber GF. Cytokine storm and sepsis disease pathogenesis. Semin Immunopathol. 2017;39(5):517-28.

43. Jamal J-A, Economou CJP, Lipman J, Roberts JA. Improving antibiotic dosing in special situations in the ICU: burns, renal replacement therapy and extracorporeal membrane oxygenation. Curr Opin Crit Care. 2012;18(5):460-71.

44. Shekar K, Fraser JF, Taccone FS, Welch S, Wallis SC, Mullany DV, et al. The combined effects of extracorporeal membrane oxygenation and renal replacement therapy on 
meropenem pharmacokinetics: a matched cohort study. Crit Care. 2014;18(6):565.

45. SAFE Study Investigators, Finfer S, Bellomo R, McEvoy S, Lo SK, Myburgh J, Neal B, Norton R. Effect of baseline serum albumin concentration on outcome of resuscitation with albumin or saline in patients in intensive care units: analysis of data from the saline versus albumin fluid evaluation (SAFE) study. BMJ. 2006; 18;333(7577):1044. https://doi.org/10.1136/bmj.38985.398704. $7 \mathrm{C}$.

46. Roberts JA, Pea F, Lipman J. The clinical relevance of plasma protein binding changes. Clinical pharmacokinetics. 2013;52(1):1-8. https://doi.org/10.1007/s40262-012-0018-5.

47. Zeitlinger MA, Derendorf H, Mouton JW, Cars O, Craig WA, Andes D, et al. Protein binding: do we ever learn? Antimicrob Agents Chemother. 2011;55(7):3067-74.

48. Pavez N, Kattan E, Vera M, Ferri G, Valenzuela ED, Alegría $\mathrm{L}$, et al. Hypoxia-related parameters during septic shock resuscitation: Pathophysiological determinants and potential clinical implications. Ann Transl Med. 2020;8(12):784.

49. Morgan ET. Impact of infectious and inflammatory disease on cytochrome P450-mediated drug metabolism and pharmacokinetics. Clin Pharmacol Ther. 2009;85(4):434-8.

50. Carré JE, Singer M. Cellular energetic metabolism in sepsis: the need for a systems approach. Biochim Biophys Acta Bioenerg. 2008;1777(7-8):763-71.

51. Smith BS, Yogaratnam D, Levasseur-Franklin KE, Forni A, Fong J. Introduction to drug pharmacokinetics in the critically ill patient. Chest. 2012;141(5):1327-36.

52. Adnan S, Ratnam S, Kumar S, Paterson D, Lipman J, Roberts $\mathrm{J}$, et al. Select critically ill patients at risk of augmented renal clearance: experience in a Malaysian intensive care unit. Anaesth Intensive Care. 2014;42(6):715-22.

53. Udy AA, Varghese JM, Altukroni M, Briscoe S, McWhinney BC, Ungerer JP, et al. Subtherapeutic initial $\beta$-lactam concentrations in select critically Ill patients: association between augmented renal clearance and low trough drug concentrations. Chest. 2012;142(1):30-9.

54. Koeze J, Keus F, Dieperink W, Van der Horst ICC, Zijlstra JG, Van Meurs M. Incidence, timing and outcome of AKI in critically ill patients varies with the definition used and the addition of urine output criteria. BMC Nephrol. 2017;18(1):1-9.

55. van den Akker JPC, Egal M, Groeneveld JAB. Invasive mechanical ventilation as a risk factor for acute kidney injury in the critically ill: A systematic review and meta-analysis. Crit Care. 2013;17(3):R98. https://doi.org/10.1186/cc12743.

56. Updated L. BEST ( Biomarkers, EndpointS, and other Tools ) Resource. 2021;(Md).

57. Lippi G. Sepsis biomarkers: past, present and future. Clin Chem Lab Med. 2019;57(9):1281-3.

58. Aulin L, De Lange D, Saleh M, Graaf P, Völler S, Van Hasselt C. Biomarker-guided individualization of antibiotic therapy. Clin Pharmacol Ther. 2021;9:110.

59. Bréchot N, Hékimian G, Chastre J, Luyt CE. Procalcitonin to guide antibiotic therapy in the ICU. Int J Antimicrob Agents. 2015;46:S19-24.

60. Branche A, Neeser O, Mueller B, Schuetz P. Procalcitonin to guide antibiotic decision making. Curr Opin Infect Dis. 2019;32(2):130-5.

61. Honore PM, Redant S, De Bels D. Reliability of biomarkers of sepsis during extracorporeal therapies: the clinician needs to know what is eliminated and what is not. Crit Care. 2020;24(1):8-11.

62. Kushner I. The phenomenon of the acute phase response. Ann N Y Acad Sci. 1982;389:39-48.

63. Dowton SB, Colten HR. Acute phase reactants in inflammation and infection. Semin Hematol. 1988;25(2):84-90.
64. Miller PR, Munn DD, Meredith JW, Chang MC. Systemic inflammatory response syndrome in the trauma intensive care unit: who is infected? J Trauma. 1999;47(6):1004-8.

65. Gilbert DN. Procalcitonin as a biomarker in respiratory tract infection. Clin Infect Dis an Off Publ Infect Dis Soc Am. 2011;52(Suppl 4):S346-50.

66. Gabay C, Kushner I. Acute-phase proteins and other systemic responses to inflammation. N Engl J Med. 1999;340(6):448-54.

67. Mikacenic C, Hahn WO, Price BL, Harju-Baker S, Katz $\mathrm{R}$, Kain $\mathrm{KC}$, et al. Biomarkers of endothelial activation are associated with poor outcome in critical illness. PLoS ONE. 2015;10(10):1-13.

68. Ríos-Toro JJ, Márquez-Coello M, García-Álvarez JM, MartínAspas A, Rivera-Fernández R, De Benito AS, et al. Soluble membrane receptors, interleukin 6 , procalcitonin and $\mathrm{C}$ reactive protein as prognostic markers in patients with severe sepsis and septic shock. PLoS ONE. 2017;12(4):1-18.

69. Gibot S, Béné MC, Noel R, Massin F, Guy J, Cravoisy A, et al. Combination biomarkers to diagnose sepsis in the critically ill patient. Am J Respir Crit Care Med. 2012;186(1):65-71.

70. Grover V, Pantelidis P, Soni N, Takata M, Shah PL, Wells AU, et al. A biomarker panel (Bioscore) incorporating monocytic surface and soluble TREM-1 has high discriminative value for ventilator-associated pneumonia: A prospective observational study. PLoS ONE. 2014;9(10):1-8.

71. Dolin HH, Papadimos TJ, Stepkowski S, Chen X, Pan ZK. A novel combination of biomarkers to herald the onset of sepsis prior to the manifestation of symptoms. Shock. 2018;49(4):364-70.

72. Li Z, Wang H, Liu J, Chen B, Li G. Serum soluble triggering receptor expressed on myeloid cells-1 and procalcitonin can reflect sepsis severity and predict prognosis: a prospective cohort study. Mediators Inflamm. 2014;641039.

73. Liu B, Chen YX, Yin Q, Zhao YZ, Li CS. Diagnostic value and prognostic evaluation of Presepsin for sepsis in an emergency department. Crit Care. 2013;17(5):R244.

74. Jämsä J, Ala-Kokko T, Huotari V, Ohtonen P, Savolainen ER, Syrjälä H. Neutrophil CD64, C-reactive protein, and procalcitonin in the identification of sepsis in the ICU-Post-test probabilities. J Crit Care. 2018;1(43):139-42.

75. Døllner H, Vatten L, Austgulen R. Early diagnostic markers for neonatal sepsis: Comparing C-reactive protein, interleukin-6, soluble tumour necrosis factor receptors and soluble adhesion molecules. J Clin Epidemiol. 2001;54(12):1251-7.

76. Zeng M, Chang M, Zheng H, Li B, Chen Y, He W, et al. Clinical value of soluble urokinase-type plasminogen activator receptor in the diagnosis, prognosis, and therapeutic guidance of sepsis. Am J Emerg Med. 2016;34(3):375-80.

77. Fabre V, Karaba S, Amoah J, Robinson M, Jones G, Dzintars K, et al. The role of procalcitonin in antibiotic decision-making in Covid-19 infection. Infect Control Hosp Epidemiol. 2021. https:// doi.org/10.1017/ice.2021.175.

78. Sims CR, Nguyen TC, Mayeux PR. Could biomarkers direct therapy for the septic patient? J Pharmacol Exp Ther. 2016;357(2):228-39.

79. Thorsted A, Nielsen EI, Friberg LE. Pharmacodynamics of immune response biomarkers of interest for evaluation of treatment effects in bacterial infections. Int $\mathrm{J}$ Antimicrob Agents. 2020;56(3):106059. https://doi.org/10.1016/j.ijantimicag.2020. 106059 .

80. Ince C, Mayeux PR, Nguyen T, Gomez H, Kellum JA, Ospina-Tascón GA, et al. The endothelium in sepsis. Shock. 2016;45(3):259-70.

81. Alphonsus CS, Rodseth RN. The endothelial glycocalyx: a review of the vascular barrier. Anaesthesia. 2014;69(7):777-84. 
82. Woodcock TE, Woodcock TM. Revised Starling equation and the glycocalyx model of transvascular fluid exchange: an improved paradigm for prescribing intravenous fluid therapy. Br J Anaesth. 2012;108(3):384-94.

83. Wiesinger A, Peters W, Chappell D, Kentrup D, Reuter S, Pavenstädt $\mathrm{H}$, et al. Nanomechanics of the endothelial glycocalyx in experimental sepsis. PLoS ONE. 2013;8(11):e80905.

84. Chelazzi C, Villa G, Mancinelli P, De Gaudio AR, Adembri C. Glycocalyx and sepsis-induced alterations in vascular permeability. Crit Care. 2015;19(1):26.

85. Fleck A, Raines G, Hawker F, Trotter J, Wallace PI, Ledingham IM, et al. Increased vascular permeability: a major cause of hypoalbuminaemia in disease and injury. Lancet (London, England). 1985;1(8432):781-4.

86. Nieuwdorp M, Meuwese MC, Mooij HL, van Lieshout MHP, Hayden A, Levi M, et al. Tumor necrosis factor-alpha inhibition protects against endotoxin-induced endothelial glycocalyx perturbation. Atherosclerosis. 2009;202(1):296-303.

87. Nelson A, Berkestedt I, Schmidtchen A, Ljunggren L, Bodelsson M. Increased levels of glycosaminoglycans during septic shock: relation to mortality and the antibacterial actions of plasma. Shock. 2008;30(6):623-7.

88. Ostrowski SR, Gaïni S, Pedersen C, Johansson PI. Sympathoadrenal activation and endothelial damage in patients with varying degrees of acute infectious disease: an observational study. J Crit Care. 2015;30(1):90-6.

89. Puskarich MA, Cornelius DC, Tharp J, Nandi U, Jones AE. Plasma syndecan-1 levels identify a cohort of patients with severe sepsis at high risk for intubation after large-volume intravenous fluid resuscitation. J Crit Care. 2016;36:125-9.

90. Steppan J, Hofer S, Funke B, Brenner T, Henrich M, Martin E, et al. Sepsis and major abdominal surgery lead to flaking of the endothelial glycocalix. J Surg Res. 2011;165(1):136-41.

91. Dogné S, Flamion B. Endothelial glycocalyx impairment in disease: focus on hyaluronan shedding. Am J Pathol. 2020;190(4):768-80.

92. Schmidt EP, Overdier KH, Sun X, Lin L, Liu X, Yang Y, et al. Urinary glycosaminoglycans predict outcomes in septic shock and acute respiratory distress syndrome. Am J Respir Crit Care Med. 2016;194(4):439-49.

93. Pauly D, Hamed S, Behnes M, Lepiorz D, Lang S, Akin I, et al. Endothelial cell-specific molecule-1/endocan: diagnostic and prognostic value in patients suffering from severe sepsis and septic shock. J Crit Care. 2016;31(1):68-75.

94. Scherpereel A, Depontieu F, Grigoriu B, Cavestri B, Tsicopoulos A, Gentina T, et al. Endocan, a new endothelial marker in human sepsis. Crit Care Med. 2006;34(2):532-7.

95. De Freitas CN, Gaudet A, Portier L, Tsicopoulos A, Mathieu D, Lassalle P. Endocan, sepsis, pneumonia, and acute respiratory distress syndrome. Crit Care. 2018;22(1):280.

96. Fiedler U, Reiss Y, Scharpfenecker M, Grunow V, Koidl S, Thurston G, et al. Angiopoietin-2 sensitizes endothelial cells to TNF-alpha and has a crucial role in the induction of inflammation. Nat Med. 2006;12(2):235-9.

97. Scharpfenecker M, Fiedler U, Reiss Y, Augustin HG. The Tie-2 ligand angiopoietin-2 destabilizes quiescent endothelium through an internal autocrine loop mechanism. J Cell Sci. 2005;118(Pt 4):771-80.

98. Fisher J, Douglas JJ, Linder A, Boyd JH, Walley KR, Russell JA. Elevated plasma angiopoietin-2 levels are associated with fluid overload, organ dysfunction, and mortality in human septic shock. Crit Care Med. 2016;44(11):2018-27.

99. Fang Y, Li C, Shao R, Yu H, Zhang Q, Zhao L. Prognostic significance of the angiopoietin-2/angiopoietin-1 and angiopoietin-1/ Tie-2 ratios for early sepsis in an emergency department. Crit Care. 2015;19(1):1-11.
100. Ricciuto DR, Dos Santos CC, Hawkes M, Toltl LJ, Conroy AL, Rajwans N, et al. Angiopoietin-1 and angiopoietin-2 as clinically informative prognostic biomarkers of morbidity and mortality in severe sepsis. Crit Care Med. 2011;39(4):702-10.

101. Yang KY, Liu KT, Chen YC, Chen CS, Lee YC, Perng RP, et al. Plasma soluble vascular endothelial growth factor receptor-1 levels predict outcomes of pneumonia-related septic shock patients: a prospective observational study. Crit Care. 2011;15(1):1-11.

102. Levi M, Opal SM. Coagulation abnormalities in critically ill patients. Crit Care. 2006;10(4):222.

103. Semeraro N, Ammollo CT, Semeraro F, Colucci M. Coagulopathy of acute sepsis. Semin Thromb Hemost. 2015;41(6):650-8.

104. Muñoz-Guillén NM, León-López R, de la Cal-Ramírez MA, Dueñas-Jurado JM. Síndrome de fuga capilar sistémica: hipoalbuminemia, hemoconcentración y shock A propósito de un caso. SEMERGEN. 2014;40(2):2-5.

105. Amitrano L, Guardascione MA, Brancaccio V, Balzano A. Coagulation disorders in liver disease. Semin Liver Dis. 2002;22(1):83-96.

106. Kudo D, Goto T, Uchimido R, Hayakawa M, Yamakawa K, Abe $\mathrm{T}$, et al. Coagulation phenotypes in sepsis and effects of recombinant human thrombomodulin: an analysis of three multicentre observational studies. Crit Care. 2021;25(1):1-11.

107. Kinasewitz GT, Yan SB, Basson B, Comp P, Russell JA, Cariou $A$, et al. Universal changes in biomarkers of coagulation and inflammation occur in patients with severe sepsis, regardless of causative micro-organism [ISRCTN74215569]. Crit Care. 2004;8(2):82-90.

108. Federici AB. The factor VIII/von Willebrand factor complex: basic and clinical issues. Haematologica. 2003;88(6):EREPO2.

109. Chang JC. Sepsis and septic shock: Endothelial molecular pathogenesis associated with vascular microthrombotic disease. Thromb J. 2019;17(1):1-19.

110. Lupu C, Herlea O, Tang H, Lijnen RH, Lupu F. Plasmin-dependent proteolysis of tissue factor pathway inhibitor in a mouse model of endotoxemia. J Thromb Haemost. 2013;11(1):142-8.

111. Mihajlovic DM, Lendak DF, Draskovic BG, Mikic ASN, Mitic GP, Cebovic TN, et al. Thrombomodulin is a strong predictor of multiorgan dysfunction syndrome in patients with sepsis. Clin Appl Thromb. 2015;21(5):469-74.

112. Lin SM, Wang YM, Lin HC, Lee KY, Da HC, Liu CY, et al. Serum thrombomodulin level relates to the clinical course of disseminated intravascular coagulation, multiorgan dysfunction syndrome, and mortality in patients with sepsis. Crit Care Med. 2008;36(3):683-9.

113. Tipoe TL, Wu WKK, Chung L, Gong M, Dong M, Liu T, et al. Plasminogen activator inhibitor 1 for predicting sepsis severity and mortality outcomes: a systematic review and meta-analysis. Front Immunol. 2018;9:1-6.

114. Plautz WE, Matthay ZA, Rollins-Raval MA, Raval JS, Kornblith LZ, Neal MD. Von Willebrand factor as a thrombotic and inflammatory mediator in critical illness. Transfusion. 2020;60(S3):S158-66.

115. Ware LB, Eisner MD, Thompson BT, Parsons PE, Matthay MA. Significance of Von Willebrand factor in septic and nonseptic patients with acute lung injury. Am J Respir Crit Care Med. 2004;170(7):766-72.

116. Zhang Q, Li C. Risk stratification and prognostic evaluation of endothelial cell-specific molecule1, von Willebrand factor, and a disintegrin-like and metalloprotease with thrombospondin type 1 motif for sepsis in the emergency department: an observational study. Exp Ther Med. 2019;17(6):4527-35. https://doi.org/10. 3892/etm.2019.7485.

117. Peetermans M, Meyers S, Liesenborghs L, Vanhoorelbeke K, De Meyer SF, Vandenbriele C, et al. Von Willebrand factor and 
ADAMTS13 impact on the outcome of Staphylococcus aureus sepsis. J Thromb Haemost. 2020;18(3):722-31.

118. Paulus P, Jennewein C, Zacharowski K. Biomarkers of endothelial dysfunction: can they help us deciphering systemic inflammation and sepsis? Biomark Biochem Indic Expo Response Susceptibility Chem. 2011;16(Suppl 1):S11-21.

119. Vanderschueren S, De Weerdt A, Malbrain M, Vankersschaever D, Frans E, Wilmer A, et al. Thrombocytopenia and prognosis in intensive care. Crit Care Med. 2000;28(6):1871-6.

120. Simmons J, Pittet JF. The coagulopathy of acute sepsis. Curr Opin Anaesthesiol. 2015;28(2):227-36.

121. MacLeod JBA, Lynn M, McKenney MG, Cohn SM, Murtha M. Early coagulopathy predicts mortality in trauma. J Trauma. 2003;55(1):39-44.

122. Adamzik M, Hamburger T, Petrat F, Peters J, de Groot H, Hartmann M. Free hemoglobin concentration in severe sepsis: methods of measurement and prediction of outcome. Crit Care. 2012;16(4):R125.

123. Rodelo JR, De La Rosa G, Valencia ML, Ospina S, Arango CM, Gómez CI, et al. D-dimer is a significant prognostic factor in patients with suspected infection and sepsis. Am J Emerg Med. 2012;30(9):1991-9.

124. Iba T, Di NM, Levy JH, Kitamura N, Thachil J. New criteria for sepsis-induced coagulopathy (SIC) following the revised sepsis definition: a retrospective analysis of a nationwide survey. BMJ Open. 2017;7(9):e017046.

125. Taylor FBJ, Toh CH, Hoots WK, Wada H, Levi M. Towards definition, clinical and laboratory criteria, and a scoring system for disseminated intravascular coagulation. Thromb Haemost. 2001;86(5):1327-30.

126. Cordemans C, De Laet I, Van Regenmortel N, Schoonheydt K, Dits H, Huber W, et al. Fluid management in critically ill patients: the role of extravascular lung water, abdominal hypertension, capillary leak, and fluid balance. Ann Intensive Care. 2012;2(Suppl 1):S1. https://doi.org/10.1186/ 2110-5820-2-S1-S1.

127. Post EH, Kellum JA, Bellomo R, Vincent JL. Renal perfusion in sepsis: from macro- to microcirculation. Kidney Int. 2017;91(1):45-60.

128. Dixon B. The role of microvascular thrombosis in sepsis. Anaesth Intensive Care. 2004;32(5):619-29.

129. De Backer D, Donadello K, Sakr Y, Ospina-Tascon G, Salgado $\mathrm{D}$, Scolletta S, et al. Microcirculatory alterations in patients with severe sepsis: impact of time of assessment and relationship with outcome. Crit Care Med. 2013;41(3):791-9.

130. Bateman RM, Sharpe MD, Ellis CG. Bench-to-bedside review: microvascular dysfunction in sepsis-hemodynamics, oxygen transport, and nitric oxide. Crit Care. 2003;7(5):359-73.

131. Zanotti Cavazzoni SL, Dellinger RP. Hemodynamic optimization of sepsis-induced tissue hypoperfusion. Crit Care. 2006;10(SUPPL. 3):1-8.

132. Mesquida J, Masip J, Gili G, Artigas A, Baigorri F. Thenar oxygen saturation measured by near infrared spectroscopy as a noninvasive predictor of low central venous oxygen saturation in septic patients. Intensive Care Med. 2009;35(6):1106-9.

133. Perner A, Haase N, Wiis J, White JO, Delaney A. Central venous oxygen saturation for the diagnosis of low cardiac output in septic shock patients. Acta Anaesthesiol Scand. 2010;54(1):98-102.

134. Zhang Z, Xu X, Chen K. Lactate clearance as a useful biomarker for the prediction of all-cause mortality in critically ill patients: a systematic review study protocol. BMJ Open. 2014;4(5):e004752.

135. Casserly B, Phillips GS, Schorr C, Dellinger RP, Townsend SR, Osborn TM, et al. Lactate measurements in sepsis-induced tissue hypoperfusion: results from the Surviving Sepsis Campaign database. Crit Care Med. 2015;43(3):567-73.
136. Mikkelsen ME, Miltiades AN, Gaieski DF, Goyal M, Fuchs BD, Shah CV, et al. Serum lactate is associated with mortality in severe sepsis independent of organ failure and shock. Crit Care Med. 2009;37(5):1670-7.

137. Rhodes A, Evans LE, Alhazzani W, Levy MM, Antonelli M, Ferrer R, et al. Surviving sepsis campaign: international guidelines for management of sepsis and septic shock: 2016. Intensive Care Med. 2017;43(3):304-77.

138. Gibot S. On the origins of lactate during sepsis. Crit Care. 2012;16(5):151.

139. Suetrong B, Walley KR. Lactic acidosis in sepsis: it's not all anaerobic: implications for diagnosis and management. Chest. 2016;149(1):252-61.

140. Chertoff J, Chisum M, Garcia B, Lascano J. Lactate kinetics in sepsis and septic shock: a review of the literature and rationale for further research. J Intensive Care. 2015;6(3):39.

141. Srivastava B, Gimson A. Hepatic changes in systemic infection. Best Pract Res Clin Gastroenterol. 2013;27(4):485-95.

142. Yan J, Li S, Li S. The role of the liver in sepsis. Int Rev Immunol. 2014;33(6):498-510.

143. Kobashi H, Toshimori J, Yamamoto K. Sepsis-associated liver injury: Incidence, classification and the clinical significance. Hepatol Res. 2013;43(3):255-66.

144. Park GR, Pichard L, Tinel M, Larroque C, Elston A, Domerque $\mathrm{J}$, et al. What changes drug metabolism in critically ill patients? Two preliminary studies in isolated human hepatocytes. Anaesthesia. 1994;49(3):188-91.

145. Jacob A, Zhou M, Wu R, Wang P. The role of hepatic cytochrome P-450 in sepsis. Int J Clin Exp Med. 2009;2(3):203-11.

146. Dorn C, Nowak H, Weidemann C, Martini S, Zeitlinger M, Adamzik M, et al. Decreased protein binding of moxifloxacin in patients with sepsis? GMS Infect Dis. 2017;5:Doc03.

147. Grensemann J, Busse D, König C, Roedl K, Jäger W, Jarczak D, et al. Acute-on-chronic liver failure alters meropenem pharmacokinetics in critically ill patients with continuous hemodialysis: an observational study. Ann Intensive Care. 2020;10(1).

148. Patel JJ, Taneja A, Niccum D, Kumar G, Jacobs E, Nanchal R. The association of serum bilirubin levels on the outcomes of severe sepsis. J Intensive Care Med. 2015;30(1):23-9.

149. Yang K, Battista C, Woodhead JL, Stahl SH, Mettetal JT, Watkins PB, et al. Systems pharmacology modeling of druginduced hyperbilirubinemia: Differentiating hepatotoxicity and inhibition of enzymes/transporters. Clin Pharmacol Ther. 2017;101(4):501-9.

150. Büdingen FV, Gonzalez D, Tucker AN, Derendorf H. Relevance of liver failure for anti-infective agents: from pharmacokinetic alterations to dosage adjustments. Ther Adv Infect Dis. 2014;2(1):17-42. https://doi.org/10.1177/2049936113 519089.

151. Verbeeck RK. Pharmacokinetics and dosage adjustment in patients with hepatic dysfunction. Eur J Clin Pharmacol. 2008;64(12):1147-61. https://doi.org/10.1007/ s00228-008-0553-z.

152. Korth JM, Baird-bellaire SJ, Patat AA, Troy SM, Böhmer GM, Gleiter $\mathrm{CH}$, et al. Pharmacokinetics and safety of a single intravenous dose of the antibiotic tigecycline in patients with cirrhosis. J Clin Pharmacol. 2011;51(1):93-101.

153. Jensen JUS, Peters L, Itenov TS, Bestle M, Thormar KM, Mohr TT, et al. Biomarker-assisted identification of sepsis-related acute liver impairment: a frequent and deadly condition in critically ill patients. Clin Chem Lab Med. 2019;57(9):1422-31.

154. Traynor J, Mactier R, Geddes CC, Fox JG. How to measure renal function in clinical practice. BMJ. 2006;333(7571):733-7.

155. Seller-Pérez G, Herrera-Gutiérrez ME, Maynar-Moliner J, Sánchez-Izquierdo-Riera JA, Marinho A, do Pico JL. Estimating 
kidney function in the critically ill patients. Crit Care Res Pract. 2013; p. 721810.

156. Bargnoux A-S, Kuster N, Cavalier E, Piéroni L, Souweine J-S, Delanaye P, et al. Serum creatinine: advantages and pitfalls. J Lab Precis Med. 2018;3:71-71.

157. Kees MG, Minichmayr IK, Moritz S, Beck S, Wicha SG, Kees $\mathrm{F}$, et al. Population pharmacokinetics of meropenem during continuous infusion in surgical ICU patients. J Clin Pharmacol. 2016;56(3):307-15.

158. Isla A, Rodríguez-Gascón A, Trocóniz IF, Bueno L, Solinís MA, Maynar J, et al. Population pharmacokinetics of meropenem in critically ill patients undergoing continuous renal replacement therapy. Clin Pharmacokinet. 2008;47(3):173-80.

159. Pai MP, Cojutti P, Pea F. Pharmacokinetics and pharmacodynamics of continuous infusion meropenem in overweight, obese, and morbidly obese patients with stable and unstable kidney function: a step toward dose optimization for the treatment of severe gram-negative bacterial infecti. Clin Pharmacokinet. 2015;54(9):933-41.

160. Nei AM, Kashani KB, Dierkhising R, Barreto EF. Predictors of augmented renal clearance in a heterogeneous ICU population as defined by creatinine and cystatin C. Nephron. 2020;144(7):31320. https://doi.org/10.1159/000507255.

161. Suzuki A, Imanishi Y, Nakano S, Niwa T, Ohmori T, Shirai $\mathrm{K}$, et al. Usefulness of serum cystatin $\mathrm{C}$ to determine the dose vancomycin in critically ill patients. J Pharm Pharmacol. 2010;62(7):901-7.

162. Delanaye P, Cavalier E, Morel J, Mehdi M, Maillard N, Claisse $\mathrm{G}$, et al. Detection of decreased glomerular filtration rate in intensive care units: serum cystatin $\mathrm{C}$ versus serum creatinine. BMC Nephrol. 2014;15:9.

163. Mårtensson J, Bell M, Oldner $\mathrm{A}, \mathrm{Xu} \mathrm{S}$, Venge $\mathrm{P}$, Martling $\mathrm{CR}$. Neutrophil gelatinase-associated lipocalin in adult septic patients with and without acute kidney injury. Intensive Care Med. 2010;36(8):1333-40.

164. Tu Y, Wang H, Sun R, Ni Y, Ma L, Xv F, et al. Urinary netrin-1 and KIM-1 as early biomarkers for septic acute kidney injury. Ren Fail. 2014;36(10):1559-63.

165. Mishra J, Dent C, Tarabishi R, Mitsnefes MM, Ma Q, Kelly C, et al. Neutrophil gelatinase-associated lipocalin (NGAL) as a biomarker for acute renal injury after cardiac surgery. Lancet (London, England). 2005;365(9466):1231-8.

166. Seymour CW, Liu VX, Iwashyna TJ, Brunkhorst FM, Rea TD, Scherag A, et al. Assessment of clinical criteria for sepsis for the third international consensus definitions for sepsis and septic shock (sepsis-3). JAMA. 2016;315(8):762-74.

167. Rhodes A, Evans LE, Alhazzani W, Levy MM, Antonelli M, Ferrer R, et al. Surviving sepsis campaign: international guidelines for management of sepsis and septic shock: 2016. Crit Care Med. 2017;45:486-552.

168. Bruegger D, Schwartz L, Chappell D, Jacob M, Rehm M, Vogeser M, et al. Release of atrial natriuretic peptide precedes shedding of the endothelial glycocalyx equally in patients undergoing on- and off-pump coronary artery bypass surgery. Basic Res Cardiol. 2011;106(6):1111-21.

169. Hippensteel JA, Uchimido R, Tyler PD, Burke RC, Han X, Zhang $\mathrm{F}$, et al. Intravenous fluid resuscitation is associated with septic endothelial glycocalyx degradation. Crit Care. 2019;23(1):1-10.

170. Jhanji S, Stirling S, Patel N, Hinds CJ, Pearse RM. The effect of increasing doses of norepinephrine on tissue oxygenation and microvascular flow in patients with septic shock. Crit Care Med. 2009;37(6):1961-6.

171. Bangash MN, Kong M-L, Pearse RM. Use of inotropes and vasopressor agents in critically ill patients. Br J Pharmacol. 2012;165(7):2015-33.
172. Gatti M, Pea F. Antimicrobial dose reduction in continuous renal replacement therapy: myth or real need? A practical approach for guiding dose optimization of novel antibiotics. Clin Pharmacokinet. 2021;60(10):1271-89. https://doi.org/10.1007/ s40262-021-01040-y.

173. Mulla H, Pooboni S. Population pharmacokinetics of vancomycin in patients receiving extracorporeal membrane oxygenation. $\mathrm{Br}$ J Clin Pharmacol. 2005;60(3):265-75.

174. Dager WE, King JH. Aminoglycosides in intermittent hemodialysis: pharmacokinetics with individual dosing. Ann Pharmacother. 2006;40(1):9-14.

175. Pea F, Viale P, Pavan F, Furlanut M. Pharmacokinetic considerations for antimicrobial therapy in patients receiving renal replacement therapy. Clin Pharmacokinet. 2007;46(12):997-1038.

176. Westermann I, Gastine S, Müller C, Rudolph W, Peters F, Bloos F, et al. Population pharmacokinetics and probability of target attainment in patients with sepsis under renal replacement therapy receiving continuous infusion of meropenem: sustained lowefficiency dialysis and continuous veno-venous haemodialysis. Br J Clin Pharmacol. 2021;87(11):4293-303. https://doi.org/10. 1111/bcp.14846.

177. Jain R, Chung SM, Jain L, Khurana M, Lau SWJ, Lee JE, et al. Implications of obesity for drug therapy: Limitations and challenges. Clin Pharmacol Ther. 2011;90(1):77-89.

178. Schwameis R, Zeitlinger M. Methods to measure target site penetration of antibiotics in critically ill patients. Curr Clin Pharmacol. 2013;8(1):46-58.

179. Schroepf S, Burau D, Muench H-G, Derendorf H, Zeitlinger M, Genzel-Boroviczény $\mathrm{O}$, et al. Microdialysis sampling to monitor target-site vancomycin concentrations in septic infants: a feasible way to close the knowledge gap. Int J Antimicrob Agents. 2021;58(4):106405.

180. Wicha SG, Märtson AG, Nielsen EI, Koch BCP, Friberg LE, Alffenaar JW, et al. From therapeutic drug monitoring to modelinformed precision dosing for antibiotics. Clin Pharmacol Ther. 2021;109(4):928-41.

181. Schmitt L, Zoller M, Minichmayr I, Scharf C, Huisinga W, Zander J, et al. Development of a dosing algorithm for meropenem in critically ill patients based on a population pharmacokinetic/pharmacodynamic analysis. Int J Antimicrob Agents. 2019;1:54.

182. Rao GG, Landersdorfer CB. Antibiotic pharmacokinetic/pharmacodynamic modelling: MIC, pharmacodynamic indices and beyond. Int J Antimicrob Agents. 2021;58(2):106368.

183. Cunio CB, Uster DW, Carland JE, Buscher H, Liu Z, Brett J, et al. Towards precision dosing of vancomycin in critically ill patients: an evaluation of the predictive performance of pharmacometric models in ICU patients. Clin Microbiol Infect. 2021;27(5):783. e7-783.e14.

184. Kofoed K, Andersen O, Kronborg G, Tvede M, Petersen J, Eugen-Olsen J, et al. Use of plasma C-reactive protein, procalcitonin, neutrophils, macrophage migration inhibitory factor, soluble urokinase-type plasminogen activator receptor, and soluble triggering receptor expressed on myeloid cells- 1 in combination to diagnose infections. Crit Care. 2007;11(2):1-10.

185. Eidizadeh A, Asif AR, von Ahsen N, Binder L, Schnelle M. Differences in procalcitonin measurements between three BRAHMS-partnered immunoassays (Liaison, Elecsys and Architect). Vol. 57, Clinical chemistry and laboratory medicine. Germany; 2019. p. e207-10.

186. Chambliss AB, Hayden J, Colby JM. Evaluation of procalcitonin immunoassay concordance near clinical decision points. Clin Chem Lab Med. 2019;57(9):1414-21.

187. Schuetz P, Wirz Y, Sager R, Christ-Crain M, Stolz D, Tamm $\mathrm{M}$, et al. Effect of procalcitonin-guided antibiotic treatment on 
mortality in acute respiratory infections: a patient level metaanalysis. Lancet Infect Dis. 2018;18(1):95-107.

188. Pierrakos C, Vincent JL. Sepsis biomarkers: a review. Crit Care. 2010;14(1):1-18

189. Pierrakos C, Velissaris D, Bisdorff M, Marshall JC, Vincent JL. Biomarkers of sepsis: Time for a reappraisal. Crit Care. 2020;24(1):1-15.

190. Reinhart K, Bauer M, Riedemann NC, Hartog CS. New approaches to sepsis: Molecular diagnostics and biomarkers. Clin Microbiol Rev. 2012;25(4):609-34.

191. Märtson AG, Sturkenboom MGG, Stojanova J, Cattaneo D, Hope $\mathrm{W}$, Marriott D, et al. How to design a study to evaluate therapeutic drug monitoring in infectious diseases? Clin Microbiol Infect. 2020;26(8):1008-16.

192. Singer M, Deutschman CS, Seymour C, Shankar-Hari M, Annane $\mathrm{D}$, Bauer M, et al. The third international consensus definitions for sepsis and septic shock (sepsis-3). JAMA. 2016;315:801-10.

193. Nicolau DP. Pharmacokinetic and pharmacodynamic properties of meropenem. Clin Infect Dis. 2008;47(Suppl 1):S32-40. https://doi.org/10.1086/590064.

194. Mouton JW, van den Anker JN. Meropenem Clinical Pharmacokinetics. Clin Pharmacokinet. 1995;28(4):275-86.

195. Gower PE, Dash CH. The pharmacokinetics of cefuroxime after intravenous injection. Eur J Clin Pharmacol. 1977;12(3):221-7.

196. Douglas A, Udy AA, Wallis SC, Jarrett P, Stuart J, Lassig-Smith $\mathrm{M}$, et al. Plasma and tissue pharmacokinetics of cefazolin in patients undergoing elective and semielective abdominal aortic aneurysm open repair surgery. Antimicrob Agents Chemother. 2011;55(11):5238-42.

197. Kirby WM, Regamey C. Pharmacokinetics of cefazolin compared with four other cephalosporins. J Infect Dis. 1973;128(Suppl):S341-6.

198. Sörgel F, Kinzig M. Pharmacokinetic characteristics of piperacillin/tazobactam. Intensive Care Med. 1994;20(3 Supplement):14-20.

199. Sörgel F, Kinzig M. The chemistry, pharmacokinetics and tissue distribution of piperacillin/tazobactam. J Antimicrob Chemother. 1993;31(Suppl A):39-60.

200. Acred P, Brown DM, Turner DH, Wilson MJ. Pharmacology and chemotherapy of ampicillin-a new broad-spectrum penicillin. $\mathrm{Br}$ J Pharmacol Chemother. 1962;18(2):356-69.

201. Aronoff SC, Jacobs MR, Johenning S, Yamabe S. Comparative activities of the beta-lactamase inhibitors YTR 830, sodium clavulanate, and sulbactam combined with amoxicillin or ampicillin. Antimicrob Agents Chemother. 1984;26(4):580-2.

202. Brown RM, Wise R, Andrews JM, Hancox J. Comparative pharmacokinetics and tissue penetration of sulbactam and ampicillin after concurrent intravenous administration. Antimicrob Agents Chemother. 1982;21(4):565-7.

203. Nicolau DP, De Waele J, Kuti JL, Caro L, Larson KB, Yu B, et al. Pharmacokinetics and pharmacodynamics of ceftolozane/ tazobactam in critically ill patients with augmented renal clearance. Int J Antimicrob Agents. 2021;57(4):106299. https://doi. org/10.1016/j.ijantimicag.2021.106299.

204. Miller B, Hershberger E, Benziger D, Trinh MM, Friedland I. Pharmacokinetics and safety of intravenous ceftolozanetazobactam in healthy adult subjects following single and multiple ascending doses. Antimicrob Agents Chemother. 2012;56(6):3086-91.

205. Zhanel GG, Chung P, Adam H, Zelenitsky S, Denisuik A, Schweizer F, et al. Ceftolozane/tazobactam: A novel cephalosporin/ $\beta$-lactamase inhibitor combination with activity against multidrug-resistant gram-negative bacilli. Drugs. 2014;74(1):31-51.

206. Wilson AP. Clinical pharmacokinetics of teicoplanin. Clin Pharmacokinet. 2000;39(3):167-83.
207. Rybak MJ. The pharmacokinetic and pharmacodynamic properties of vancomycin. Clin Infect Dis. 2006;42(Supplement_1):S35-9.

208. Yamasaki K, Sakurama K, Nishi K, Watanabe H, Maruyama $\mathrm{T}$, Seo $\mathrm{H}$, et al. Characterization of the interaction of daptomycin with site II on human serum albumin. J Pharm Sci. 2020;109(9):2919-24.

209. Lee BL, Sachdeva M, Chambers HF. Effect of protein binding of daptomycin on MIC and antibacterial activity. Antimicrob Agents Chemother. 1991;35(12):2505-8.

210. Dvorchik BH, Brazier D, DeBruin MF, Arbeit RD. Daptomycin pharmacokinetics and safety following administration of escalating doses once daily to healthy subjects. Antimicrob Agents Chemother. 2003;47(4):1318-23.

211. Raz R. Fosfomycin: an old-new antibiotic. Clin Microbiol Infect. 2012;18(1):4-7.

212. Wenzler E, Ellis-Grosse EJ, Rodvold KA. Pharmacokinetics, safety, and tolerability of single-dose intravenous (ZTI-01) and oral fosfomycin in healthy volunteers. Antimicrob Agents Chemother. 2017;61(9):e00775-17. https://doi.org/10.1128/AAC. 00775-17.

213. Frossard M, Joukhadar C, Erovic BM, Dittrich P, Mrass PE, Houte MVAN, et al. Distribution and antimicrobial activity of fosfomycin in the interstitial fluid of human soft tissues. Antimicrob Agent Chemother. 2000;44(10):2728-32.

214. Barbour A, Schmidt S, Ma B, Schiefelbein L, Rand KH, Burkhardt $\mathrm{O}$, et al. Clinical pharmacokinetics and pharmacodynamics of tigecycline. Clin Pharmacokinet. 2009;48(9):575-84.

215. Muralidharan G, Micalizzi M, Speth J, Raible D, Troy S. Pharmacokinetics of tigecycline after single and multiple doses in healthy subjects. Antimicrob Agents Chemother. 2005;49(1):220-9.

216. Vance-Bryan K, Guay DR, Rotschafer JC. Clinical pharmacokinetics of ciprofloxacin. Clin Pharmacokinet. 1990;19(6):434-61.

217. Stass H, Kubitza D. Pharmacokinetics and elimination of moxifloxacin after oral and intravenous administration in man. J Antimicrob Chemother. 1999;43(Suppl B):83-90.

218. Lamp KC, Freeman CD, Klutman NE, Lacy MK. Pharmacokinetics and pharmacodynamics of the nitroimidazole antimicrobials. Clin Pharmacokinet. 1999;36(5):353-73.

219. Siber GR, Echeverria P, Smith AL, Paisley JW, Smith DH. Pharmacokinetics of gentamicin in children and adults. J Infect Dis. 1975;132(6):637-51.

220. Bauer LA, Blouin RA. Influence of age on amikacin pharmacokinetics in patients without renal disease. Comparison with gentamicin and tobramycin. Eur J Clin Pharmacol. 1983;24(5):639-42.

221. Vogelman B, Gudmundsson S, Leggett J, Turnidge J, Ebert S, Craig WA. Correlation of antimicrobial pharmacokinetic parameters with therapeutic efficacy in an animal model. J Infect Dis. 1988;158(4):831-47.

222. Lalak NJ, Morris DL. Azithromycin clinical pharmacokinetics. Clin Pharmacokinet. 1993;25(5):370-4.

223. Magréault S, Roy C, Launay M, Sermet-Gaudelus I, Jullien V. Pharmacokinetic and pharmacodynamic optimization of antibiotic therapy in cystic fibrosis patients: current evidences, gaps in knowledge and future directions. Clin Pharmacokinet. 2021;60(4):409-45. https://doi.org/10.1007/ s40262-020-00981-0.

224. Periti P, Mazzei T, Mini E, Novelli A. Clinical pharmacokinetic properties of the macrolide antibiotics. Effects of age and various pathophysiological states (Part I). Clin Pharmacokinet. 1989;16(4):193-214.

225. Couet W, Grégoire N, Gobin P, Saulnier PJ, Frasca D, Marchand $\mathrm{S}$, et al. Pharmacokinetics of colistin and colistimethate sodium 
after a single 80-mg intravenous dose of CMS in young healthy volunteers. Clin Pharmacol Ther. 2011;89(6):875-9.

226. Dryden MS. Linezolid pharmacokinetics and pharmacodynamics in clinical treatment. J Antimicrob Chemother. 2011;66(SUPPL. 4):7-15

227. Calandra T, Baumgartner JD, Grau GE, Wu MM, Lambert PH, Schellekens J, et al. Prognostic values of tumor necrosis factor/ cachectin, interleukin-1, interferon-alpha, and interferon-gamma in the serum of patients with septic shock. Swiss-Dutch J5 Immunoglobulin Study Group. J Infect Dis. 1990 May;161(5):982-7.

228. Küster H, Weiss M, Willeitner AE, Detlefsen S, Jeremias I, Zbojan J, et al. Interleukin-1 receptor antagonist and interleukin-6 for early diagnosis of neonatal sepsis 2 days before clinical manifestation. Lancet (London, England). 1998;352(9136):1271-7.

229. Ma L, Zhang H, Ling YY, Zhi GW, Qun MY, Bo WY, et al. Role of interleukin-6 to differentiate sepsis from non-infectious systemic inflammatory response syndrome. Cytokine. 2016;88:126-35.

230. Zhou M, Cheng S, Yu J, Lu Q. Interleukin-8 for diagnosis of neonatal sepsis: a meta-analysis. PLoS ONE. 2015;10(5):1-12.

231. Kraft R, Herndon DN, Finnerty CC, Cox RA, Song J, Jeschke MG. Predictive value of IL-8 for sepsis and severe infections after burn injury: a clinical study. Shock. 2015;43(3):222-7.

232. Matera G, Puccio R, Giancotti A, Quirino A, Pulicari MC, Zicca E, et al. Impact of interleukin-10, soluble CD25 and interferon- $\gamma$ on the prognosis and early diagnosis of bacteremic systemic inflammatory response syndrome: A prospective observational study. Crit Care. 2013;17(2):R64.

233. Waage A, Brandtzaeg P, Halstensen A, Kierulf P, Espevik T. The complex pattern of cytokines in serum from patients with meningococcal septic shock. Association between interleukin 6, interleukin 1, and fatal outcome. J Exp Med. 1989;169(1):333-8.

234. Hofstra CL, Van Ingrid A, Hofman G, Nijkamp FP, Jardieu PM, Van Oosterhout AJM. Differential effects of endogenous and exogenous interferon- $\gamma$ on immunoglobulin $\mathrm{E}$, cellular infiltration, and airway responsiveness in a murine model of allergic asthma. Am J Respir Cell Mol Biol. 1998;19(5):826-35.

235. Bhavsar I, Miller CS, Al-Sabbagh M. Macrophage Inflammatory Protein-1 Alpha (MIP-1 alpha)/CCL3: As a Biomarker. Preedy VR, Patel VB, editors. Gen Methods Biomark Res their Appl. 2015;223-49.

236. Chong IW, Lin SR, Hwang JJ, Huang MS, Wang TH, Tsai MS, et al. Expression and regulation of macrophage inflammatory protein-2 gene by vanadium in mouse macrophages. Inflammation. 2000;24(2):127-39.

237. Aquino VM, Cost C, Gomez A, Bowers DC, Ramilo O, Ahmad $\mathrm{N}$, et al. Predictive value of interleukin- 5 and monocyte chemotactic protein- 1 for bacteremia in children with febrile neutropenia. J Pediatr Hematol Oncol. 2012;34(6):e241-5.

238. Barre M, Behnes M, Hamed S, Pauly D, Lepiorz D, Lang S, et al. Revisiting the prognostic value of monocyte chemotactic protein 1 and interleukin-6 in the sepsis-3 era. J Crit Care. 2018;43:21-8.

239. Nakamura M, Takeuchi T, Naito K, Shirakawa K, Hosaka Y, Yamasaki F, et al. Early elevation of plasma soluble CD14 subtype, a novel biomarker for sepsis, in a rabbit cecal ligation and puncture model. Crit Care. 2008;12(2):P194.

240. Yoon SH, Kim EH, Kim HY, Ahn JG. Presepsin as a diagnostic marker of sepsis in children and adolescents: a systemic review and meta-analysis. BMC Infect Dis. 2019;19(1):1-11.

241. Aliu-Bejta A, Atelj A, Kurshumliu M, Dreshaj S, Baršić B. Presepsin values as markers of severity of sepsis. Int J Infect Dis. 2020;95:1-7.

242. Hoffmann JJML. Neutrophil CD64: a diagnostic marker for infection and sepsis. Clin Chem Lab Med. 2009;47(8):903-16.

243. Yeh C-F, Wu C-C, Liu S-H, Chen K-F. Comparison of the accuracy of neutrophil $\mathrm{CD} 64$, procalcitonin, and $\mathrm{C}$-reactive protein for sepsis identification: a systematic review and meta-analysis. Ann Intensive Care.

244. Tang Z, Qin D, Tao M, Lv K, Chen S, Zhu X, et al. Examining the utility of the CD64 index compared with other conventional indices for early diagnosis of neonatal infection. Sci Rep. 2018;8(1):1-7.

245. Drewry AM, Ablordeppey EA, Murray ET, Beiter ER, Walton $\mathrm{AH}$, Hall MW, et al. Comparison of monocyte human leukocyte antigen-DR expression and stimulated tumor necrosis factor alpha production as outcome predictors in severe sepsis: a prospective observational study. Crit Care. 2016;20(1):334.

246. Shankar-Hari M, Datta D, Wilson J, Assi V, Stephen J, Weir CJ, et al. Early PREdiction of sepsis using leukocyte surface biomarkers: the ExPRES-sepsis cohort study. Intensive Care Med. 2018;44(11):1836-48.

247. Krivan S, Kapelouzou A, Vagios S, Tsilimigras DI, Katsimpoulas $\mathrm{M}$, Moris D, et al. Increased expression of Toll-like receptors 2, 3, 4 and 7 mRNA in the kidney and intestine of a septic mouse model. Sci Rep. 2019;9(1):1-9.

248. Ten Oever J, Kox M, van de Veerdonk FL, Mothapo KM, Slavcovici A, Jansen TL, et al. The discriminative capacity of soluble Toll-like receptor (sTLR)2 and sTLR4 in inflammatory diseases. BMC Immunol. 2014;19(15):55.

249. Holst B, Szakmany T, Raby A-C, Hamlyn V, Durno K, Hall JE, et al. Soluble Toll-like receptor 2 is a biomarker for sepsis in critically ill patients with multi-organ failure within $12 \mathrm{~h}$ of ICU admission. Intensive care Med Exp. 2017;5(1):2.

250. Chang W, Peng F, Meng SS, Xu JY, Yang Y. Diagnostic value of serum soluble triggering expressed receptor on myeloid cells 1 (sTREM-1) in suspected sepsis: a meta-analysis. BMC Immunol. 2020;21(1):2. https://doi.org/10.1186/s12865-020-0332-x.

251. Jeong SJ, Song YG, Kim CO, Kim HW, Ku NS, Han SH, et al. Measurement of plasma sTREM-1 in patients with severe sepsis receiving early goal-directed therapy and evaluation of its usefulness. Shock. 2012;37(6):574-8.

252. Wright SW, Lovelace-Macon L, Hantrakun V, Rudd KE, Teparrukkul P, Kosamo S, et al. sTREM-1 predicts mortality in hospitalized patients with infection in a tropical, middle-income country. BMC Med. 2020;18(1):1-9.

253. Huttunen R, Syrjänen J, Vuento R, Hurme M, Huhtala H, Laine J, et al. Plasma level of soluble urokinase-type plasminogen activator receptor as a predictor of disease severity and case fatality in patients with bacteraemia: a prospective cohort study. J Intern Med. 2011;270(1):32-40.

254. Pregernig A, Müller M, Held U, Beck-Schimmer B. Prediction of mortality in adult patients with sepsis using six biomarkers: a systematic review and meta-analysis. Ann Intensive Care. 2019;9(1):125. https://doi.org/10.1186/s13613-019-0600-1.

255. Ni W, Han Y, Zhao J, Cui J, Wang K, Wang R, et al. Serum soluble urokinase-Type plasminogen activator receptor as a biological marker of bacterial infection in adults: a systematic review and meta-Analysis. Sci Rep. 2016;6(November):1-8.

256. Monnet E, Lapeyre G, van Poelgeest E, Jacqmin P, de Graaf K, Reijers J, et al. Evidence of NI-0101 pharmacological activity, an anti-TLR4 antibody, in a randomized phase I dose escalation study in healthy volunteers receiving LPS. Clin Pharmacol Ther. 2017;101(2):200-8.

257. Póvoa P, Coelho L, Almeida E, Fernandes A, Mealha R, Moreira $\mathrm{P}$, et al. C-reactive protein as a marker of infection in critically ill patients. Clin Microbiol Infect. 2005;11(2):101-8.

258. Meisner M, Schmidt J, Hüttner H, Tschaikowsky K. The natural elimination rate of procalcitonin in patients with normal and impaired renal function. Intensive Care Med. 2000;26(Suppl 2):S212-6 
259. Bacli C, Sungurtekin H, Gürses E, Sungurtekin U, Kaptanoğlu B. Usefulness of procalcitonin for diagnosis of sepsis in the intensive care unit. Crit Care. 2003;7:85-90.

260. Pavcnik-Arnol M, Hojker S, Derganc M. Lipopolysaccharidebinding protein in critically ill neonates and children with suspected infection: comparison with procalcitonin, interleukin-6, and C-reactive protein. Intensive Care Med. 2004;30(7):1454-60.

261. de Kruif MD, Lemaire LC, Giebelen IA, Struck J, Morgenthaler NG, Papassotiriou J, et al. The influence of corticosteroids on the release of novel biomarkers in human endotoxemia. Intensive Care Med. 2008;34(3):518-22.

262. Angeletti S, Battistoni F, Fioravanti M, Bernardini S, Dicuonzo G. Procalcitonin and mid-regional pro-adrenomedullin test combination in sepsis diagnosis. Clin Chem Lab Med. 2013;51(5):1059-67.

263. Cicuendez R, Nogales L, Bueno A, Gonzalez De Zarate S, Calvo D, Andres C, et al. Prognostic value of proadrenomedulin in severe sepsis and septic shock is independent of etiology and focus of infection. Intensive Care Med Exp. 2015;3(Suppl 1):A518.

264. Uusitalo-Seppälä R, Huttunen R, Aittoniemi J, Koskinen P, Leino A, Vahlberg T, et al. Pentraxin 3 (PTX3) is associated with severe sepsis and fatal disease in emergency room patients with suspected infection: a prospective cohort study. PLoS ONE. 2013;8(1):1-8

265. Lee YT, Gong M, Chau A, Wong WT, Bazoukis G, Wong SH, et al. Pentraxin-3 as a marker of sepsis severity and predictor of mortality outcomes: a systematic review and meta-analysis. J Infect. 2018;76(1):1-10.

266. Hamed S, Behnes M, Pauly D, Lepiorz D, Barre M, Becher T, et al. Diagnostic value of Pentraxin-3 in patients with sepsis and septic shock in accordance with latest sepsis-3 definitions. BMC Infect Dis. 2017;17(1):554.

267. Teisner B, Brandslund I, Grunnet N, Hansen LK, Thellesen J, Svehag SE. Acute complement activation during an anaphylactoid reaction to blood transfusion and the disappearance rate of $\mathrm{C} 3 \mathrm{c}$ and $\mathrm{C} 3 \mathrm{~d}$ from the circulation. J Clin Lab Immunol. 1983;12(2):63-7.

268. Eichenberger EM, Dagher M, Ruffin F, Park L, Hersh L, Sivapalasingam $\mathrm{S}$, et al. Complement levels in patients with bloodstream infection due to Staphylococcus aureus or Gram-negative bacteria. Eur J Clin Microbiol Infect Dis. 2020;39(11):2121-31.

269. Schmidt de Oliveira-Netto AC, Morello LG, Dalla-Costa LM, Petterle RR, Fontana RM, Conte D, et al. Procalcitonin, C-reactive protein, albumin, and blood cultures as early markers of sepsis diagnosis or predictors of outcome: a prospective analysis. Clin Pathol (Thousand Oaks, Ventur County, Calif). 2019;18(12):2632010X19847673.

270. Takegawa R, Kabata D, Shimizu K, Hisano S, Ogura H, Shintani A, et al. Serum albumin as a risk factor for death in patients with prolonged sepsis: an observational study. J Crit Care. 2019;51:139-44.

271. Karampela I, Chrysanthopoulou E, Simitsis P, Skyllas G, Christodoulatos GS, Antonakos G, et al. C-reactive protein/albumin ratio as a prognostic biomarker in critically ill septic patients: a prospective study. Eur Respir J. 2020;56(suppl 64):2751.

272. Smart L, Bosio E, Macdonald SPJ, Dull R, Fatovich DM, Neil C, et al. Glycocalyx biomarker syndecan-1 is a stronger predictor of respiratory failure in patients with sepsis due to pneumonia, compared to endocan. J Crit Care. 2018;47:93-8.

273. Schmidt EP, Li G, Li L, Fu L, Yang Y, Overdier KH, et al. The circulating glycosaminoglycan signature of respiratory failure in critically ill adults. J Biol Chem. 2014;289(12):8194-202.

274. Seo K, Kitazawa T, Yoshino Y, Koga I, Ota Y. Characteristics of serum endocan levels in infection. PLoS ONE. 2015;10(4):1-12.
275. Mihajlovic DM, Lendak DF, Brkic SV, Draskovic BG, Mitic GP, Novakov Mikic AS, et al. Endocan is useful biomarker of survival and severity in sepsis. Microvasc Res. 2014;93:92-7.

276. Tian R, Wang X, Pan T, Li R, Wang J, Liu Z, et al. Plasma PTX3, MCP1 and Ang2 are early biomarkers to evaluate the severity of sepsis and septic shock. Scand J Immunol. 2019;90(6):e12823.

277. Davis JS, Yeo TW, Piera KA, Woodberry T, Celermajer DS, Stephens DP, et al. Angiopoietin-2 is increased in sepsis and inversely associated with nitric oxide-dependent microvascular reactivity. Crit Care. 2010;14(3):R89-R89.

278. Amalakuhan B, Habib SA, Mangat M, Reyes LF, Rodriguez AH, Hinojosa CA, et al. Endothelial adhesion molecules and multiple organ failure in patients with severe sepsis. Cytokine. 2016;88:267-73.

279. Shapiro NI, Schuetz P, Yano K, Sorasaki M, Parikh SM, Jones AE, et al. The association of endothelial cell signaling, severity of illness, and organ dysfunction in sepsis. Crit Care. 2010;14(5):R182.

280. Fang Y, Li C, Shao R, Yu H, Zhang Q. The role of biomarkers of endothelial activation in predicting morbidity and mortality in patients with severe sepsis and septic shock in intensive care: a prospective observational study. Thromb Res. 2018;171(September):149-54.

281. Schuetz P, Jones AE, Aird WC, Shapiro NI. Endothelial cell activation in emergency department patients with sepsis-related and non-sepsis-related hypotension. Shock. 2011;36(2):104-8.

282. Gijsen M, Dreesen E, Van Daele R, Annaert P, Debaveye Y, Wauters J, et al. Pharmacokinetic/pharmacodynamic target attainment based on measured versus predicted unbound ceftriaxone concentrations in critically ill patients with pneumonia: an observational cohort study. Antibiotics. 2021;10(5):557.

283. Kümpers P, van Meurs M, David S, Molema G, Bijzet J, Lukasz A, et al. Time course of angiopoietin-2 release during experimental human endotoxemia and sepsis. Crit Care. 2009;13(3):1-9.

284. Karlsson S, Pettilä V, Tenhunen J, Lund V, Hovilehto S, Ruokonen E. Vascular endothelial growth factor in severe sepsis and septic shock. Anesth Analg. 2008;106(6):1820-6.

285. Martín-Rodríguez F, López-Izquierdo R, del Pozo VC, Delgado-Benito JF, Ortega GJ, Castro Villamor MA, et al. Association of prehospital oxygen saturation to inspired oxygen ratio with 1-, 2-, and 7-day mortality. JAMA Netw Open. 2021;4(4):e215700-e215700.

286. Houwink API, Rijkenberg S, Bosman RJ, van der Voort PHJ. The association between lactate, mean arterial pressure, central venous oxygen saturation and peripheral temperature and mortality in severe sepsis: a retrospective cohort analysis. Crit Care. 2016;20:56.

287. Maheshwari K, Nathanson BH, Munson SH, Khangulov V, Stevens $\mathrm{M}$, Badani $\mathrm{H}$, et al. The relationship between ICU hypotension and in-hospital mortality and morbidity in septic patients. Intensive Care Med. 2018;44(6):857-67.

288. Havaldar AA. Evaluation of sepsis induced cardiac dysfunction as a predictor of mortality. Cardiovasc Ultrasound. 2018;16(1):31.

289. de Castilho FM, Ribeiro ALP, da Silva JLP, Nobre V, de Sousa MR. Heart rate variability as predictor of mortality in sepsis: a prospective cohort study. PLoS ONE. 2017;12(6):e0180060-e0180060.

290. Textoris J, Fouché L, Wiramus S, Antonini F, Tho S, Martin C, et al. High central venous oxygen saturation in the latter stages of septic shock is associated with increased mortality. Crit Care. 2011;15(4):R176-R176.

291. Leone M, Blidi S, Antonini F, Meyssignac B, Bordon S, Garcin $\mathrm{F}$, et al. Oxygen tissue saturation is lower in nonsurvivors than in survivors after early resuscitation of septic shock. Anesthesiology. 2009;111(2):366-71. 
292. Lenting PJ, Christophe OD, Denis CV. von Willebrand factor biosynthesis, secretion, and clearance: connecting the far ends. Blood. 2015;125(13):2019-28.

293. Aibar J, Castro P, Espinosa G, Fernández S, Hernández C, Rinaudo M, et al. ADAMTS-13 in critically ill patients with septic syndromes and noninfectious systemic inflammatory response syndrome. Shock. 2015;43(6):556-62.

294. Azfar MF, Khan MF, Habib SS, Aseri Al Z, Zubaidi AM, Aguila DO, et al. Prognostic value of ADAMTS13 in patients with severe sepsis and septic shock. Clin Invest Med. 2017;40(2):E49-58.

295. Martin K, Borgel D, Lerolle N, Feys HB, Trinquart L, Vanhoorelbeke K, et al. Decreased ADAMTS-13 (A disintegrin-like and metalloprotease with thrombospondin type 1 repeats) is associated with a poor prognosis in sepsis-induced organ failure. Crit Care Med. 2007;35(10):2375-82.

296. Matsubara T, Yamakawa K, Umemura Y, Gando S, Ogura H, Shiraishi A, et al. Significance of plasma fibrinogen level and antithrombin activity in sepsis: a multicenter cohort study using a cubic spline model. Thromb Res. 2019;1(181):17-23.

297. Juutilainen A, Hämäläinen S, Pulkki K, Kuittinen T, Nousiainen $\mathrm{T}$, Jantunen E, et al. Biomarkers for bacteremia and severe sepsis in hematological patients with neutropenic fever: Multivariate logistic regression analysis and factor analysis. Leuk Lymphoma. 2011;52(12):2349-55.

298. Kinasewitz GT, Yan SB, Basson B, Comp P, Russell JA, Cariou $A$, et al. Universal changes in biomarkers of coagulation and inflammation occur in patients with severe sepsis, regardless of causative micro-organism [ISRCTN74215569]. Crit Care. 2004;8(2):R82-90.

299. van Vught LA, Uhel F, Ding C, van't Veer C, Scicluna BP, Peters-Sengers $\mathrm{H}$, et al. Consumptive coagulopathy is associated with a disturbed host response in patients with sepsis. J Thromb Haemost. 2021;19(4):1049-63.

300. Chopin N, Floccard B, Sobas F, Illinger J, Boselli E, Benatir F, et al. Activated partial thromboplastin time waveform analysis: a new tool to detect infection? Crit Care Med. 2006;34(6):1654-60.

301. Dempfle C-EH, Lorenz S, Smolinski M, Wurst M, West S, Houdijk WPM, et al. Utility of activated partial thromboplastin time waveform analysis for identification of sepsis and overt disseminated intravascular coagulation in patients admitted to a surgical intensive care unit. Crit Care Med. 2004;32(2):520-4.

302. Schneider CP, Angele MK, Hartl WH. Activated partial thromboplastin time waveform analysis as specific sepsis marker in cardiopulmonary bypass surgery. Crit Care. 2010;14(1):14-6.

303. Iba T, Watanabe E, Umemura Y, Wada T, Hayashida K, Kushimoto $\mathrm{S}$, et al. Sepsis-associated disseminated intravascular coagulation and its differential diagnoses. J Intensive Care. 2019;7(1):1-13.

304. Mavrommatis AC, Theodoridis T, Economou M, Kotanidou A, El Ali M, Christopoulou-Kokkinou V, et al. Activation of the fibrinolytic system and utilization of the coagulation inhibitors in sepsis: comparison with severe sepsis and septic shock. Intensive Care Med. 2001;27(12):1853-9.

305. Pettilä V, Pentti J, Pettilä M, Takkunen O, Jousela I. Predictive value of antithrombin III and serum C-reactive protein concentration in critically ill patients with suspected sepsis. Crit Care Med. 2002;30(2):271-5.

306. Wiedermann CJ. Clinical review: molecular mechanisms underlying the role of antithrombin in sepsis. Crit Care. 2006;10(1):209.

307. Agirbasli M, Eren M, Yasar S, Delil K, Goktay F, Oner ET, et al. Functionally stable plasminogen activator inhibitor- 1 in a family with cardiovascular disease and vitiligo. J Thromb Thrombolysis. 2014;38(1):50-6.
308. Koyama K, Madoiwa S, Nunomiya S, Koinuma T, Wada M, Sakata A, et al. Combination of thrombin-antithrombin complex, plasminogen activator inhibitor-1, and protein $\mathrm{C}$ activity for early identification of severe coagulopathy in initial phase of sepsis: a prospective observational study. Crit Care. 2014;18(1):R13-R13.

309. Madoiwa S, Nunomiya S, Ono T, Shintani Y, Ohmori T, Mimuro $\mathrm{J}$, et al. Plasminogen activator inhibitor 1 promotes a poor prognosis in sepsis-induced disseminated intravascular coagulation. Int J Hematol. 2006;84(5):398-405.

310. Zeerleder S, Schroeder V, Hack CE, Kohler HP, Wuillemin WA. TAFI and PAI-1 levels in human sepsis. Thromb Res. 2006;118(2):205-12.

311. Hayakawa M, Kushimoto S, Watanabe E, Goto K, Suzuki Y, Kotani T, et al. Pharmacokinetics of recombinant human soluble thrombomodulin in disseminated intravascular coagulation patients with acute renal dysfunction. Thromb Haemost. 2017;117(5):851-9.

312. Bouchard J, Malhotra R, Shah S, Kao Y-T, Vaida F, Gupta A, et al. Levels of protein $\mathrm{C}$ and soluble thrombomodulin in critically ill patients with acute kidney injury: a multicenter prospective observational study. PLoS ONE. 2015;10(3):e0120770.

313. Johansen ME, Johansson PI, Ostrowski SR, Bestle MH, Hein $\mathrm{L}$, Jensen ALG, et al. Profound endothelial damage predicts impending organ failure and death in sepsis. Semin Thromb Hemost. 2015;41(1):19-25.

314. Zhai R, Sheu CC, Su L, Gong MN, Tejera P, Chen F, et al. Serum bilirubin levels on ICU admission are associated with ARDS development and mortality in sepsis. Thorax. 2009;64(9):784-90.

315. Bhogal HK, Sanyal AJ. The molecular pathogenesis of cholestasis in sepsis. Front Biosci (Elite Ed). 2013;1(5):87-96.

316. Nesseler N, Launey Y, Aninat C, Morel F, Mallédant Y, Seguin P. Clinical review: the liver in sepsis. Crit Care. 2012;16(5):235.

317. Yao Y, Wang D, Yin Y. Advances in sepsis-associated liver dysfunction. Burn Trauma. 2014;2(3):97.

318. Ayar G, Atmaca YM, Alışık M, Erel Ö. Effects of paraoxonase, arylesterase, ceruloplasmin, catalase, and myeloperoxidase activities on prognosis in pediatric patients with sepsis. Clin Biochem. 2017;50(7-8):414-7.

319. Gudowska M, Gruszewska E, Panasiuk A, Cylwik B, Flisiak $\mathrm{R}$, Świderska M, et al. Hyaluronic acid concentration in liver diseases. Clin Exp Med. 2016;16(4):523-8.

320. Wang K, Xie S, Xiao K, Yan P, He W, Xie L. Biomarkers of sepsis-induced acute kidney injury. Biomed Res Int. 2018;24(2018):6937947.

321. Katayama S, Nunomiya S, Koyama K, Wada M, Koinuma T, Goto Y, et al. Markers of acute kidney injury in patients with sepsis: the role of soluble thrombomodulin. Crit Care. 2017;21(1):229.

322. Beier K, Eppanapally S, Bazick HS, Chang D, Mahadevappa K, Gibbons FK, et al. Elevation of blood urea nitrogen is predictive of long-term mortality in critically ill patients independent of "normal" creatinine. Crit Care Med. 2011;39(2):305-13.

323. van der Slikke EC, Star BS, de Jager VD, Leferink MBM, Klein LM, Quinten VM, et al. A high urea-to-creatinine ratio predicts long-term mortality independent of acute kidney injury among patients hospitalized with an infection. Sci Rep. 2020;10(1):1-10.

324. Törnblom S, Nisula S, Petäjä L, Vaara ST, Haapio M, Pesonen E, et al. Urine NGAL as a biomarker for septic AKI: a critical appraisal of clinical utility - data from the observational FINNAKI study. Ann Intensive Care. 2020;10(1):51. 